\title{
molecules
}

ISSN 1420-3049

www.mdpi.com/journal/molecules

Review

\section{Recent Advances in Click Chemistry Applied to Dendrimer Synthesis}

\author{
Mathieu Arseneault ${ }^{\dagger}$, Caroline Wafer $^{\dagger}$ and Jean-François Morin * \\ Département de Chimie, Université Laval, 1045 avenue de la Médecine, Pavillon Alexandre-Vachon, \\ QC G1V 0A6, Canada; E-Mails: mathieu.arseneault.1@ulaval.ca (M.A.); \\ caroline.wafer.1@ulaval.ca (C.W.) \\ $\dagger$ These authors contributed equally to this work. \\ * Author to whom correspondence should be addressed; E-Mail: jean-francois.morin@chm.ulaval.ca; \\ Tel.: +1-418-656-2812.
}

Academic Editor: Arnaud Gautier

Received: 16 April 2015 / Accepted: 12 May 2015 / Published: 20 May 2015

\begin{abstract}
Dendrimers are monodisperse polymers grown in a fractal manner from a central point. They are poised to become the cornerstone of nanoscale devices in several fields, ranging from biomedicine to light-harvesting. Technical difficulties in obtaining these molecules has slowed their transfer from academia to industry. In 2001, the arrival of the "click chemistry" concept gave the field a major boost. The flagship reaction, a modified Hüisgen cycloaddition, allowed researchers greater freedom in designing and building dendrimers. In the last five years, advances in click chemistry saw a wider use of other click reactions and a notable increase in the complexity of the reported structures. This review covers key developments in the click chemistry field applied to dendrimer synthesis from 2010 to 2015 . Even though this is an expert review, basic notions and references have been included to help newcomers to the field.
\end{abstract}

Keywords: dendrimer; dendron; click; Hüisgen cycloaddition; thiol-ene; thiol-yne; Diels-Alder 


\section{Introduction}

The click chemistry paradigm, published in 2001 [1], was quickly applied to the synthesis of new dendritic architectures [2]. Among the criteria that define click chemistry-high reaction enthalpy, high chemoselectivity, atom economy and environmental safety - the first two combined to unlock new structures that would have been otherwise unattainable. In recent years, great strides have been accomplished in the field of dendrimer synthesis and we have witnessed an increase in the complexity of the reported assemblies. Fine-tuning of reaction conditions proper to the field also resulted in noteworthy achievements. Herein we review the advances published between 2010 and early 2015 featuring click chemistry applied to dendrimer synthesis or functionalization. Our starting point is the 2010 review from the Kakkar group that had a similar focus [3]. The first aim of the present review is to offer an update of the field regarding new dendritic constructs, whether they pertain to new architectures or to a new level of complexity in design. A line had to be traced and we chose to limit ourselves to well-defined dendrimers and dendrons. Hyperbranched polymers, pseudo-dendrimers and star polymers are excluded because the lack of monodispersity in these architectures frees them from certain design constraints found in dendrimer synthesis. The synthesis of these macromolecules presents other challenges that do not overlap entirely with synthesis of dendrimers. For readers interested by that topic, there are excellent review articles [4-6]. The second goal of this review is to catalog the reaction conditions used during the years covered. Many of these have not been developed within our time scope, but they are still in use and therefore relevant to report and discuss. Special attention is also paid to the dendrimers that make specific usage of 1,2,3-triazoles. The shortness of this article forced us to make editorial choices. Nevertheless, over three hundred articles were surveyed and analyzed to write this focused review. Before discussing the novelty in a field that is now more than a decade old, basic notions must be covered, however briefly.

\section{Click Reactions Applied to Dendrimers}

\subsection{Dendrimers}

A dendrimer is a regularly branched macromolecule that splits in a controlled manner to form what resembles a tree, hence the use of the Greek root for the word tree "dendr". Counting Tomalia's initial paper on poly(amido amine) (PAMAM) where the word was coined as the starting point [7], dendrimers are now thirty years old. Numerous books [8-10] and about 22,000 articles have since been published on the topic. Their physico-chemical properties diverge so greatly from classic polymers that they are often regarded as a separate class of molecules. These differences stem almost entirely from three key features: their monodispersity, their multivalency and their globular shape. Each of these advantages has been harnessed with great imagination. The applications range from biomedical devices [11-13] to light/energy harvesting [14,15] and catalysis [16]. Yet, very few products utilizing dendrimers and only one drug have reached the market [17]. The main reason beyond this is the synthesis of dendritic scaffolds themselves. The need for highly efficient reactions that are orthogonal to each other and the difficulties to purify an increasingly ramified macromolecule have hindered transfer from academia to industry. Figure 1 presents the anatomy and the vocabulary of dendrimer chemistry. 


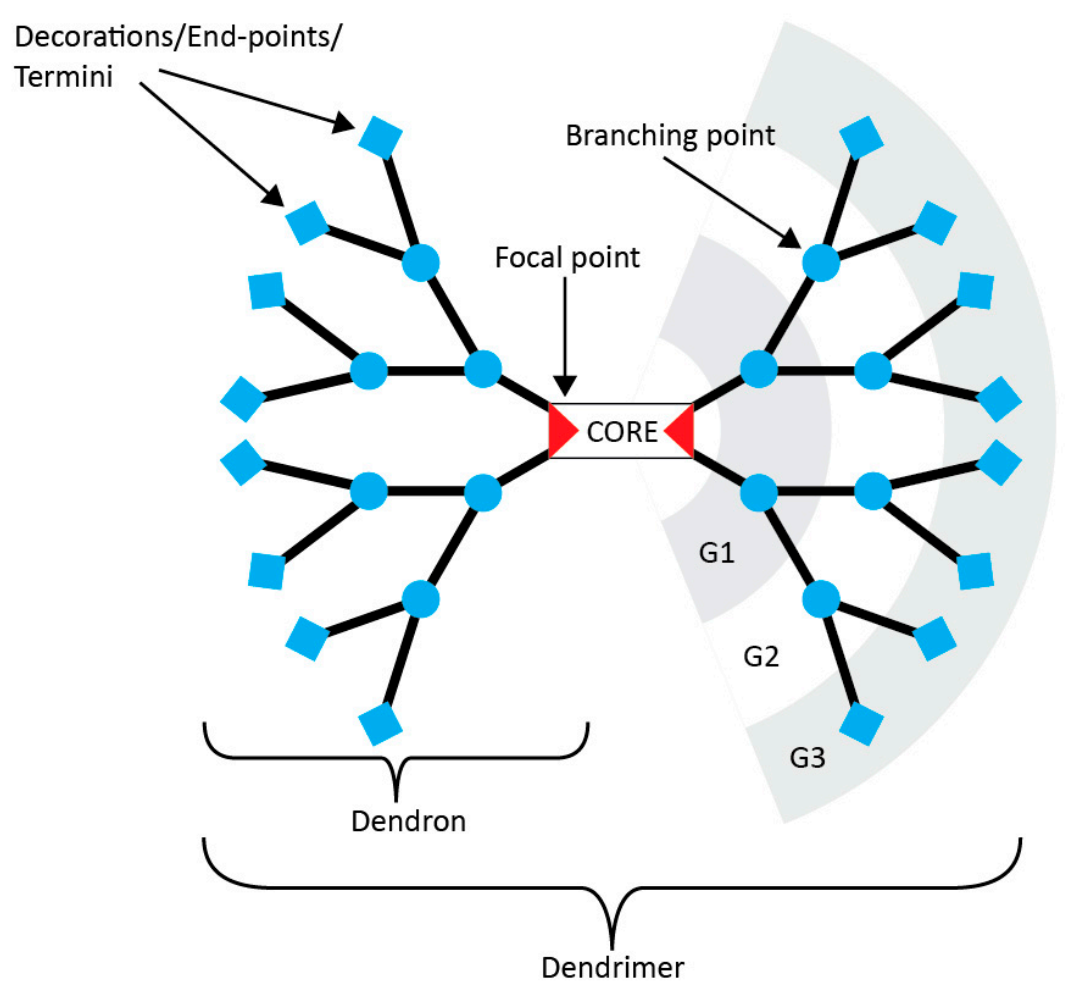

Figure 1. Anatomy of a dendrimer. This example is an $\mathrm{AB}_{2}$ type, where each branch is made of a monomer A that splits into two B monomers. "G" stands for generation.

\subsection{The Click Chemistry Paradigm Applied to Dendrimers}

Click chemistry was elaborated first and foremost around several high yielding reactions. While 95\% conversion is sometime considered "complete" in organic chemistry, it is not sufficient to build a dendrimer, especially higher generation ones. Completion at each step is crucial to maintain the purity and consequently the monodispersity of a dendrimer. Added to this stringency, the iterative two-step process in either convergent or divergent synthesis requires sturdy orthogonality. Few reactions feature both yields over $99 \%$ and good orthogonality to each other [18]. This is why click chemistry has been key to many new dendritic architectures. The atom economy and the environmental friendliness that are also criteria for a reaction to be deemed "click" are of a much lesser importance in the dendrimer community, at least from our survey. Application of click chemistry to material chemistry beyond dendrimers has been skilfully reviewed by several teams [19-21].

\subsubsection{Copper-Assisted Azide-Alkyne Cycloaddition (CuAAC)}

Sharpless et al., reported a modification of the Hüisgen [2+3] cycloaddition between an alkyne and an azide catalyzed by copper under mild conditions (Scheme 1) [22]. It was published quickly after the article describing the click concept and the reaction became so closely associated with it that the term "click" is now often used to describe this specific reaction. It accommodates both hydrophilic and hydrophobic substrates, a precious characteristic for amphiphilic macromolecules. It can also operate in a wide range of $\mathrm{pH}$ values (5-12) and proceeds at room temperature. The catalyst pair is quite benign and cheap compared to a vast majority of organometallic compounds. In light of all these advantages, it 
is not surprising that these conditions are still the most used by a wide margin. This reaction is now so common that it is often viewed as a non-issue. Yet, on many occasions, it needs to be optimized.

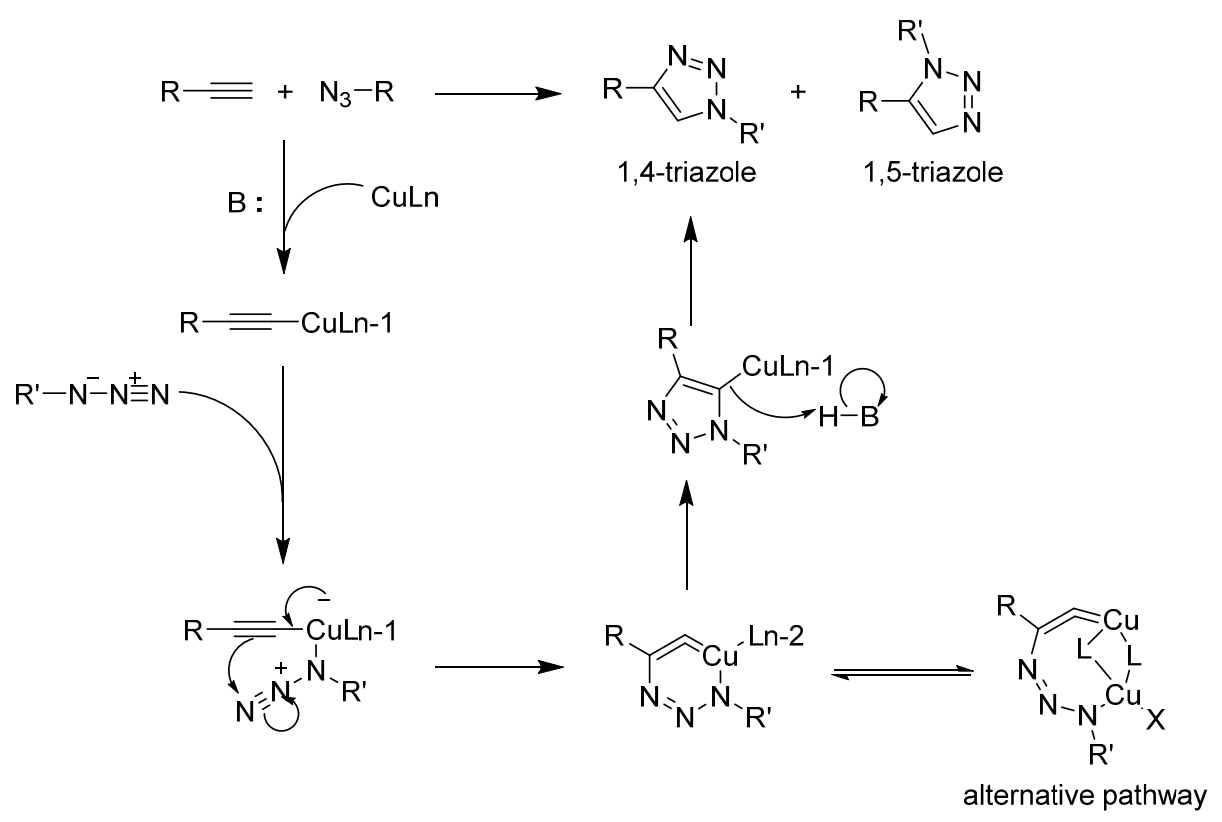

Scheme 1. The Hüisgen $[2+3]$ cycloaddition and the monomolecular version of the mechanism when it is catalyzed by copper. The alternative dinuclear transition state presented here is now widely accepted and explored by several groups [23-26].

Despite the sturdiness and versatility described above, classic CuAAC conditions can sometimes fail, especially in dendrimer synthesis and decoration. The most common shortcoming is that the $5 \%$ copper sulfate $/ 10 \%$ sodium ascorbate catalyst is insufficient to complete the reaction. Three main reasons can explain this problem. First, the catalyst load has to be adjusted as a function of the number of reacting sites on a given dendrimer, leading to catalyst loads that can become almost stoichiometric in regard of a single site [27-31]. The percent mol ratio is specified to be per coupling site in some cases and per mol of substrate in others, or simply unspecified, leaving a significant margin to be re-optimized by others. Second, metal complexation by the dendrimer substrate can become an issue depending on the nature of the branches. Catalyst has to be added until the substrate is filled. This leads to problematic purifications as discussed below. Third, deactivation of the $\mathrm{Cu}(\mathrm{I})$ catalyst to $\mathrm{Cu}(0)$ or $\mathrm{Cu}(\mathrm{II})$ is more likely to happen with a higher number of reacting sites and longer reaction times [26]. Beside adding more copper, the usual two-fold excess of sodium ascorbate may be increased to five-fold [30,32] to ensure the copper remains in the proper oxidation state. Interestingly, the exhaustive work of the Lee group shows a clear example where yields either decrease as generations go up under a given set of conditions [29], or that longer reaction times and heating have to be applied to maintain yields [33,34]. It should be noted that systematic investigation of reaction conditions is a rare thing in dendrimer synthesis mostly because of the time and costs involved in preparing substrates that can hardly relate to one another. The speed of the reaction is akin to a second order reaction in regard to the catalyst concentration [35]. Unfortunately, some dendrimers are only soluble at low concentrations, owing to their high molar mass and rigidity. This constitutes another argument in favor of a higher catalytic load. Oxidation by ambient air can shorten copper catalysts' lifespan over longer reaction times [26]. Oxidised copper can then lead to 
acetylene homo-coupling (Glaser-Hay reactions), destroying two molecules of the alkyne substrate at each turnover [36]. Carrying out the reaction under an inert atmosphere usually solves the issue.

The hydrophilicity of the solvents can sometime be unsuitable for highly hydrophobic dendrimers. Commonly used hydrophobic conditions featuring $\mathrm{CuBr}$ as the copper source is listed in Table 1 alongside all the noteworthy conditions we found. It should be noted that this condensed table only covers the last five years and readers should also consider Meldal's detailed 2008 review for more conditions [37].

Table 1. CuAAC conditions noted in dendrimer synthesis from 2010 to 2015.

\begin{tabular}{|c|c|c|c|c|c|}
\hline Catalyst & $\begin{array}{c}\text { Base/Acid/ } \\
\text { Reductant/Ligand }\end{array}$ & Solvent & Temp. & Type of Architecture & $\begin{array}{c}\text { Typical } \\
\text { Reference }\end{array}$ \\
\hline $\mathrm{CuSO}_{4}$ & $\begin{array}{l}\text { NaAsc, THPTA, } \\
\text { TBTA, Ph-COOH, } \\
\mathrm{K}_{2} \mathrm{CO}_{3}, \mathrm{NaHCO}_{3} \\
\end{array}$ & $\begin{array}{c}\mathrm{H}_{2} \mathrm{O}, \mathrm{THF}, \mathrm{DMF}, \\
t-\mathrm{BuOH}^{\mathrm{a}}, \mathrm{EtOH}^{\mathrm{a}}, \\
\mathrm{MeOH}^{\mathrm{a}}\end{array}$ & $\begin{array}{c}\mathrm{rt}, 50^{\circ} \mathrm{C}, \\
85^{\circ} \mathrm{C}^{\mathrm{b}}, \mathrm{MW}\end{array}$ & $\begin{array}{c}\text { PAMAM, Fréchet-type, } \\
\text { Percec-type, polyesters, PEG } \\
\text { branches, polypeptides, others }\end{array}$ & {$[30,31,38-40]$} \\
\hline $\mathrm{CuOAc}$ & $\begin{array}{c}\text { NaAsc, THPTA, } \\
\text { TBTA }\end{array}$ & DMF, $\mathrm{MeOH}$ & $\mathrm{rt}, 100^{\circ} \mathrm{C}$ & Polypeptides, others & {$[39,41]$} \\
\hline $\mathrm{CuI}$ & $\mathrm{Et}_{3} \mathrm{~N}, \mathrm{DIPEA}$ & DMF, THF, DCM & $\mathrm{rt}$ & $\begin{array}{l}\text { PAMAM, polyesters, } \\
\text { polypeptides, others }\end{array}$ & {$[40,42-44]$} \\
\hline $\mathrm{CuBr}$ & PMEDTA & DMF, THF & $\mathrm{rt}, 40^{\circ} \mathrm{C}$ & PEG-branches, others & {$[38,45,46]$} \\
\hline $\mathrm{CuF}_{2}$ & - & $\mathrm{MeOH}, \mathrm{H}_{2} \mathrm{O}$ & $40^{\circ} \mathrm{C}$ & Polyesters & [40] \\
\hline $\mathrm{Cu}(\mathrm{MeCN})_{4} \mathrm{PF}_{6}$ & DIPEA & $\mathrm{MeOH}, \mathrm{DCM}$ & $\mathrm{rt}$ & Peptides & [47] \\
\hline Metallic $\mathrm{Cu}$ & $\mathrm{Et}_{3} \mathrm{NH}_{4} \mathrm{Ac}$ & $\mathrm{MeOH}$ & $\begin{array}{c}\mathrm{MW}(7 \mathrm{~h}), \\
70{ }^{\circ} \mathrm{C}\end{array}$ & Phosphocarbohydrates & {$[48,49]$} \\
\hline
\end{tabular}

${ }^{\mathrm{a}}$ It has been reported that alcohols can slow the reaction, despite being frequently used [50]; ${ }^{\mathrm{b}}$ These conditions were reported to be possible due to a protection of end groups on a PAMAM [27].

The groups that first described $\mathrm{CuAAC}$ are still investigating its mechanism. The latest advance favors a dinuclear mechanism featuring two copper ions and two sets of substrates [51-53]. It is also now believed that several closely related mechanisms could be operating alongside one another. This mechanistic flexibility partially explains the efficient conversion observed in CuAAC. Astruc provided an interesting exploration of this and proposed several alternatives in his seminal 2011 article [54]. It is most likely that steric hindrance shifts the mechanism towards a mononuclear one as the dendrimer generation increases. Another key aspect of the mechanism is the need for a base to deprotonate the alkyne and help the copper to bond at the end of it. While CuAAC has been shown to proceed at pHs as low as 5 , it is often carried out at $\mathrm{pH} 8$ to 10 . Bases usually include carbonate salts and secondary or tertiary amines. In 2010, Shao et al., screened several weak organic acids added to CuAAC [55]. The argument for this modification is that a source of proton helps complete the catalytic cycle by removing the copper from the triazole. This strategy was applied to the synthesis of at least two dendrimers $[27,56]$. Given that there are few cases featuring this addition, it is too early to predict which dendritic architectures will benefit from it.

A key improvement of CuAAC over the original Hüisgen cycloaddition [57] is the possibility to perform the reaction at room temperature. Originally, the activation barrier was so steep that high temperatures had to be maintained for the reaction to proceed. It also yielded a mixture of 1,4 and 
1,5-triazoles (Scheme 1) while CuAAC only produces the 1,4-regioisomer under the proper conditions. For dendrimer synthesis, the 1,5-triazole could be much more difficult due to sterical hindrance and potentially change the behavior and accessibility of the decorating moieties. This is most likely why we could not find dendrimers assembled through the ruthenium version of CuAAC (RuAAC) since it selectively produces the 1,5-regioisomer [58]. We noted a few examples where CuAAC carried out at $50{ }^{\circ} \mathrm{C}$ still leads to the 1,4-triazole [59,60]. In such cases, the steric hindrance that slows the reaction and warrants an increase in temperature also greatly favors the proper regioisomer. In other cases, people have used microwave heating to reach high temperatures over a short period of time [30,32,61-64].

As stated earlier, copper removal can be a critical issue. Dendrimers complex copper $[65,66]$ and other metals so efficiently that they are often studied as a support to grow metallic nanoparticles [67]. Copper contamination is a concern mainly because of its in vivo toxicity [68] and its ability to quench fluorescence [69]. Several purification methods to remove copper from dendrimers have been reported and can be found in Table 2. While these procedures are sometime able to remove the quasi-totality of copper ions, their chelating ability can be surpassed by the dendrimer itself. Predicting the chelating power of a given architecture is a difficult task. Many factors come into play, but the presence of tertiary nitrogen atoms near the branching points that can act as pincers like those found in PAMAM is a good indicator. Triazoles can also act as chelating points [25].

Table 2. Methods used to remove copper from CuAAC in dendrimer synthesis from 2010 to 2015.

\begin{tabular}{clc}
\hline Method & \multicolumn{1}{c}{ Comment } & Typical Reference \\
\hline \multirow{2}{*}{ EH ${ }_{4} \mathrm{Cl}$ sat. washes } & $\begin{array}{l}\text { This is a pH 5 solution that can be basified by adding } \\
\mathrm{NH}_{4} \mathrm{OH} \text {. We found that several washes were needed. }\end{array}$ & {$[44]$} \\
\hline \multirow{2}{*}{ EDTA washes } & $\begin{array}{l}\text { Because of EDTA four pKa values, we observed a } \\
\text { great variability of pH and efficiency, depending on } \\
\text { the commercial version used. }\end{array}$ & {$[70]$} \\
\hline KCN washes & $\begin{array}{l}\text { Given the high toxicity of HCN, this solution needs to } \\
\text { be kept basic until safely discarded. }\end{array}$ & {$[71]$} \\
\hline \multirow{2}{*}{ Dialysis } & $\begin{array}{l}\text { This method is the longest and suits hydrophilic } \\
\text { dendrimers that are unfit for aqueous/organic washes. } \\
\text { Dilute EDTA can be added to the external solution. }\end{array}$ & {$[72,73]$} \\
\hline
\end{tabular}

An alternative solution adopted by researchers, especially in the biomaterial community, is to use a strongly chelated source of copper. Doing so not only prevents the dendritic substrate from capturing copper ions, but also keeps the metal in the desired oxidation state as well [25]. Steric hindrance may also favors the 1,4 isomer. The most used ones for dendrimer synthesis are shown in Figure 2. They can be removed by conventional methods such as column chromatography or aqueous washes. Two points can be derived from their structures: they are dendritic in nature and they rely on nitrogen complexation and not oxygen. This is in good agreement with a conclusion from Shao et al., who observed that acetate ligands are likely to be detrimental to CuAAC completion [54]. In 2011, Astruc further explored CuAAC through the design of dendritic catalysts [53]. Their work resulted in another small dendritic catalyst, dubbed $\mathrm{Cu}$-tren, showing great promise both in activity and in ease of preparation. Larger dendritic $[16,53,69]$ or polymeric $[74,75]$ catalysts are often reported, but have yet to be used in a routine manner. 

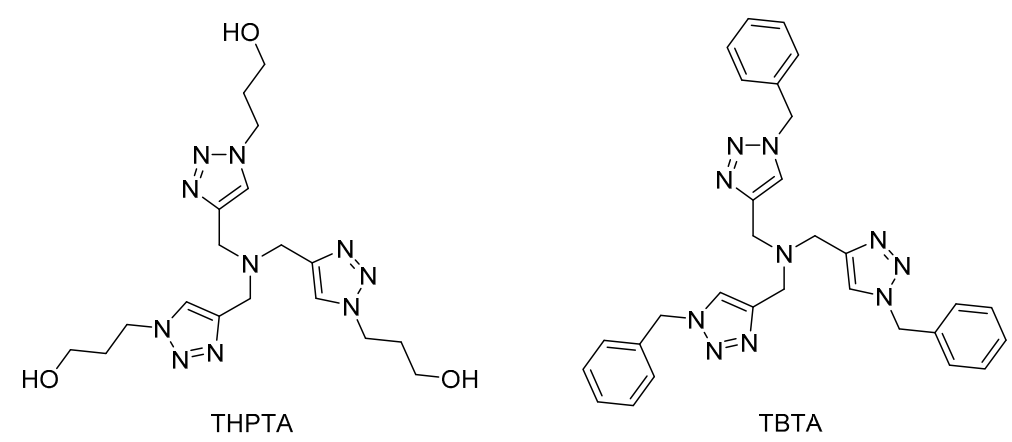

Figure 2. Tris(3-hydroxypropyltriazolylmethyl)amine (THPTA) (left) and tris-(benzyltriazolylmethyl)amine (TBTA) (right). Similar ones have been developed and studied as CuAAC ligands [25].

A well-established trend in azide-alkyne click chemistry is to forego metal catalysis altogether. Bertozzi developed a strategy relying on cycle tension release of a cyclooctyne to activate the alkyne (Figure 3) [76,77]. Strain promoted azide-alkyne cycloaddition (SPAAC) is now routinely used in dendrimer chemistry, mostly for final decoration purposes [78-80]. Its orthogonality with CuAAC has proven to be useful in creating multifunctional substrates [81,82] or Janus dendrimers [68]. As a testament to the utility of SPAAC, Bertozzi's synthons are now commercially available. Nevertheless, their bulkiness and hydrophobicity [83] added to the fact that it can hardly branch out could explain why we did not find any dendritic architecture built around it. The Baker group used a cyclooctyne bearing a fluorine atom in the vicinal position of the alkyne. This stems from the computational study carried by Goddard III [84] and experimental work by Bertozzi [77]. It showed that having electron- withdrawing groups (EWGs) conjugated with the alkyne greatly activated SPAAC. Sharpless himself noted early on that EWGs were efficient activators [22]. Application of this strategy to dendrimer synthesis is a much more recent development though. Acetylenedicarboxylic esters have been used to first decorate a highly congested low generation dendrimer by Fessner [85] and then for the branching points by Brook [86] and ourselves [87]. While very successful, these endeavors are still isolated cases. Acetylenedicarboxylic esters are notably delicate and much work remains to be done to transform the idea into a more flexible strategy. As a side note, we found a few interesting optimizations regarding the installation of azides onto dendritic scaffolds. The temperarture if the usual $\mathrm{S}_{\mathrm{N}} 2$ reaction carried out in DMF at ca. $80{ }^{\circ} \mathrm{C}$ can be lowered to $40{ }^{\circ} \mathrm{C}$ [88] or even room temperature in some cases [89]. Other azides can also be used [90] under milder conditions. In the same line of thought, Hamilton used a succinimide-based azide at room temperature [91].

A)

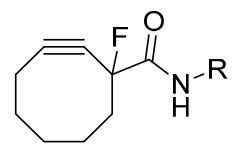

C)

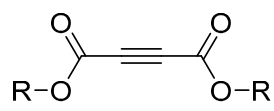

B)<smiles>[R]C(=O)N1Cc2ccccc2C#Cc2ccccc21</smiles>

D)

Figure 3. Copper-free synthons used in dendrimer synthesis (A) fluorinated cyclooctyne (B) a dibenzoazocyclooctyne variant $(\mathbf{C})$ acetylenediesters $(\mathbf{D})$ propiolic esters. 
It should be noted that the Hüisgen cycloaddition, with or without copper, features some dangers. It is exothermic and can reach hazardous temperatures with highly activated substrates. In our hands, the EWG strategy self-heated to an estimated $120^{\circ} \mathrm{C}$ in seconds and charred itself. Added to this, activated small moieties (such as acetylenecarboxylates) that react spontaneously can be highly toxic until transformed into the triazole. Moreover, synthesis and use of labile azides need to be planned carefully to prevent toxic and explosive decompositions. Usual laboratory precautions are sufficient to tackle said risks.

\subsubsection{The Thiol-ene and Thiol-yne Click Reactions}

The origin of the thiol-ene click reaction (TEC) is more diffuse than CuAAC as Hoogenboom and Lowe pointed out [92,93], but it has now evolved into a well-defined set of conditions. In its current form, TEC consists of the reaction between a terminal alkene and a thiol as shown in Scheme 2. It can either proceed through a free-radical mechanism or a nucleophilic one [94]. The former is the most popular since it can be photocatalyzed. Classic conditions are mild and orthogonal to a large spectrum of reactions, including the Michael Addition and CuAAC. All these advantages combined qualify this reaction to be seen as a "click" one. TEC was covered in details in several recent reviews [93,95-100] and we focus only on recent application to dendrimer synthesis. The wavelengths used to initiate the reaction vary from 350 to $365 \mathrm{~nm}$. For dendrimer synthesis, having fewer reactants leads to easier purifications, which can be crucial. That said, our survey showed that in most cases, a radical initiator was needed to bring the reaction to completion. Notably, 2,2'-dimethoxy-2-phenylacetophenone in substoichiometric quantities was used for this purpose in recent works [101-103]. It can be carried out in a large selection of solvents (THF, $\mathrm{MeOH}, \mathrm{H}_{2} \mathrm{O}, \mathrm{DMF}, \mathrm{DCM}$ ), usually under an inert atmosphere to avoid side reactions involving molecular oxygen. Precipitation in ether and chromatography columns are the most used purification methods we noted. Recently, Bowman et al., screened the reactivity of various vinyl and thiol units in a dendritic setting [104]. Despite being newer and less popular than $\mathrm{CuAAC}, \mathrm{TEC}$ now has its place in the toolbox of material chemists. Its tolerance toward other reactions has led to various pairs of reactions for the iterative synthesis of dendrimers in recent years. Key examples are discussed in a later section.

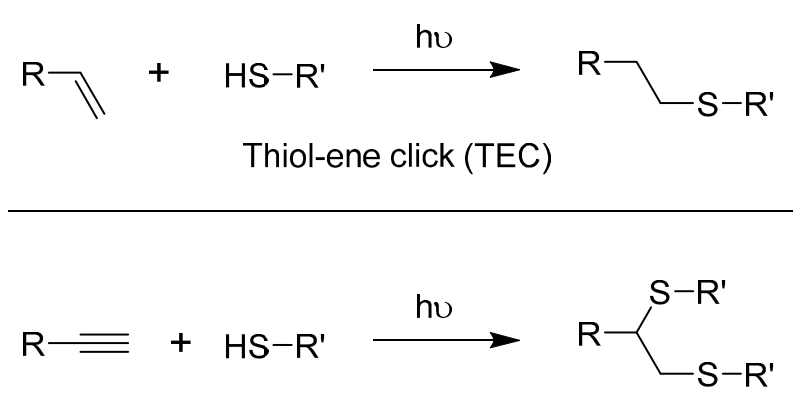

Thiol-yne click (TYC)

Scheme 2. General schemes for the thiol-ene click reaction (Top) and for the thiol-yne click reaction (Bottom).

The parent thiol-yne click reaction (TYC) functions through the same mechanism [92,105]. The difference is that once a thiol fragment has linked to the alkyne, a second reaction can occur on the 
resulting alkene. TYC is much more difficult to control in terms of regioselectivity, even more so if one aims to prevent the addition of the second thiol. This challenge is almost irrelevant in dendrimer chemistry though, as people have been using it mainly in a branching strategy $[92,106,107]$. By using the same conditions than TEC, two thiol moieties react in a predictable manner onto a terminal alkyne (Scheme 2). TYC branching points are represented as only one diastereoisomer, but researchers acknowledge the 1:1 ratio between the trans and cis isomers [103]. The effect or absence thereof of this mixture on the final functionality is sometime discussed by researchers, but without a noticeable trend yet given how recent this strategy is. While both TEC and TYC can be carried out on substituted moieties, we noted only terminal examples. TYC offers a noteworthy advantage of being orthogonal with CuAAC while sharing its substrates, namely the alkynes. Examples of how this was successfully applied to glycodendrimers are available in Section 3. Biocompatibility of TYC and TEC was partially covered in a review regarding the role of sulfur in glycodendrimers [108].

\subsubsection{The Diels-Alder (DA) Reaction}

The reaction between a diene and a dienophile (Scheme 3) viewed through the "click" lens has been covered recently $[20,109]$. The main point is that DA meets the convenient advantages offered by click reactions through atom economy, high conversion, simple conditions and good chemo and regioselectivity. Another feature of the reaction is the possibility to choose whether it is reversible or not by carefully selecting the precursors. Müllen popularized the use of cyclopentadienone as the diene to build carbon-rich dendrimers [110]. During this specific case, a carbon monoxide molecule is lost, preventing any retro Diels-Alder (rDA). According to our survey, the conditions to carry out this reaction have not evolved noticeably within the last five years, except for the use of microwave irradiation to reach $300{ }^{\circ} \mathrm{C}$ [111]. With this optimization, Bunz et al., were able to reach new levels of steric hindrance in a dendrimer. For them, DA was more reliable than organometallic coupling. Carbon-rich materials regularly feature melting points reaching $350{ }^{\circ} \mathrm{C}$, so the high temperatures needed are not an issue. Noteworthy structures published since 2010 using this strategy are detailed in Section 3.

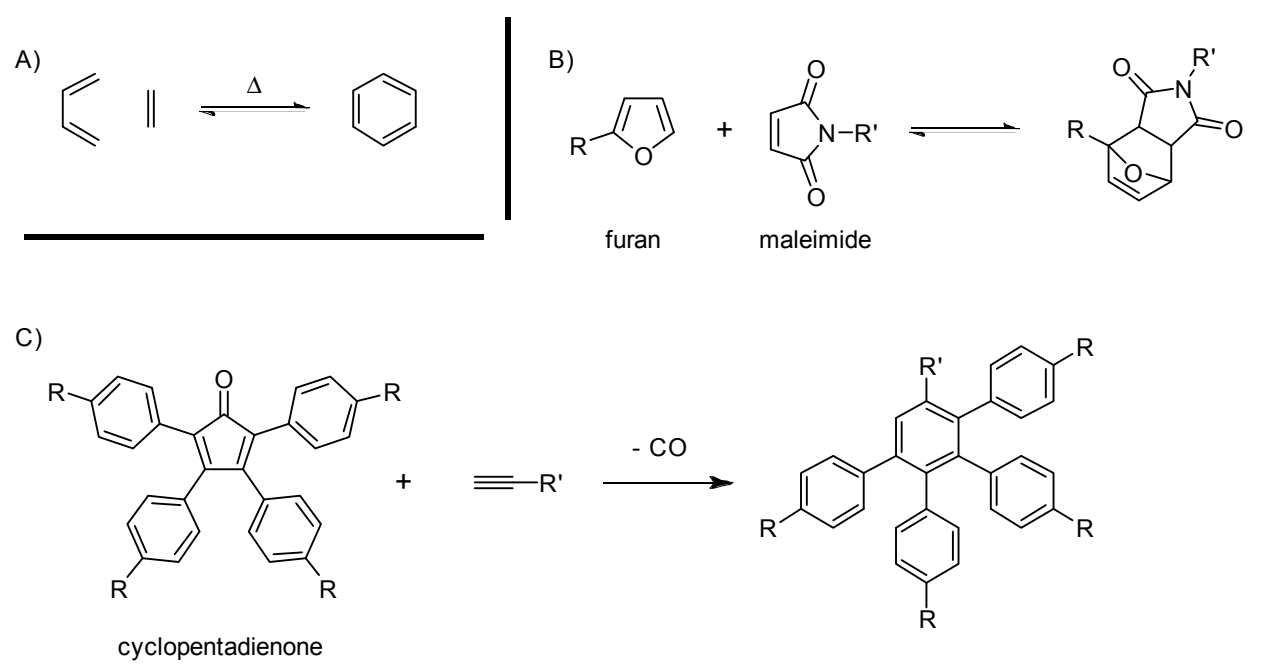

Scheme 3. General scheme for the Diels-Alder (DA) reaction (A), an example of rDA with furan and maleimide $(\mathbf{B})$ and the cyclopentadienone popularized by the Mülllen group $(\mathbf{C})$. 
DA is also used to synthesize biocompatible macromolecules $[109,112]$. Here, high temperatures can become problematic (loss of secondary and tertiary conformation, thermolabile bonds, etc.). The use of highly activated substrates alleviates this issue. For this purpose, maleimide, furan [113-118] and anthracene [115,117-119] remain the most popular ones. The compatibility of CuAAC and DA was used in several cases. Meanwhile, examples of orthogonality between DA and TEC are far rarer, but do exist. Interestingly, Bowman et al. used TEC to block the retro aspect of DA between furan and maleimide [120]. The retro character of these two synthons is well-known and is at the center of some recent self-immolatives dendrimers as discussed later on.

\subsubsection{Upcoming Click Reactions for Dendrimers}

Despite the progress of the three click reactions described above, there will always be room for new synthetic tools. Ever-growing orthogonality "unlocks" more complex materials that can be used as a lab-on-a-molecule [121], performing several reactions and detections in parallel. Beyond the need for multifunctionality, synthetic chemists need to be able to vary the nature of the linking groups at will.

Majoral and Caminade have been exploring phosphorus chemistry applied to dendrimer synthesis for several years now [122]. One of their most recent development modifies the Staudinger reaction to give it "click" attributes [123]. A Janus [123] and an "onion peel" [124] dendrimer were built with this new reaction as proof-of-concept. Other reactions that features click characteristics are being investigated for materials synthesis, such as the trans-cyclooctene/tetrazine [125] pair and Sharpless' new SuFEx reaction [126]. Both could potentially be used in dendrimer synthesis. Other potential "click reactions" have been covered by Hoogenboom [127].

\section{Structural Advances}

\subsection{Rise of Complexity}

The extended family of macromolecules bearing dendrons have been reviewed abundantly over the years [9]. Thus, we chose to focus on select aspects of novelty in recently reported structures. Nevertheless, seemingly classical designs sometime require unusual strategy and need to be discussed. The last five years have witnessed a notable increase in the complexity of published dendritic structures. Complexity often implies great difficulties in material synthesis and this is where click chemistry truly shines. Deconstructing the paradigm, one can see how features of click reactions are left behind in order to keep only the ones that unlock target structures.

\subsubsection{Difficult Decorations and other High Molar Mass Dendrimers}

Obtaining a high molar mass dendrimer may not seem like a noteworthy feat at first glance, but in order to maintain the polydispersity index under 1.1, there are certain milestones that can halt progress. Novel solutions need to be developed, either in reaction conditions or characterisation techniques. A good example is the new megadalton dendrimers published by the Müllen group [128,129]. They used the same cyclopentadienone strategy described above, but changed the shape of the branches and managed to reach $100 \mathrm{kDa}$. Extreme steric hindrance at the periphery of a dendrimer is often pointed as the main obstacle toward very high generation dendrimers or bulky decoration. Efficient conversion, 
especially in the divergent method, then becomes essential. CuAAC is often used to decorate dendrimers. Its efficiency allows the use of voluminous moieties that would otherwise be very difficult or simply impossible to put on a dendrimer. Zong, in collaboration with Baker went a step further by doing a two-stages post-functionalization of a PAMAM [81]. Other large decorations that were enabled by click chemistry include peptides [32,130-134], carbohydrates [104,135-144], DNA [140,145,146], sRNA [147] and chelated gadolinium $[131,134]$. In that area, Cloninger et al., proposed a new way to envision surface functionalization of a dendrimer using CuAAC [148]. Departing from the conventional idea of uniformly capping end groups, they proposed to actively seek a clustering of a given decorating moieties. This was done by building a smaller dendron bearing several copies of the first moieties. This clustering created larger "free zones" at the periphery, allowing for a secondary bulky decoration. Interestingly, Wagner et al., decorated a dendron with oligoamines that proved incompatible with subsequent $\mathrm{CuAAC}$, presumably because of copper trapping [149]. The solution was simply to switch the synthesis order. Fessner et al., screened several activated alkyne for CuAAC in their 2010 article and they managed to functionalize a POSS core with adamantane units [85]. The article of Bunz discussed above can also be seen as a type of difficult decoration that was enabled by click chemistry [111]. In a publication by the Tang group, propiolic acid was used with a source of copper to activate the reaction both through the catalytic and the EWG strategies at the same time to add a bulky decoration on a congested G4 dendrimer [150].

\subsubsection{Janus and Controlled 3-Face Dendrimers}

The work of Cloninger cited above is an evolution of the common statistical decoration of a given dendrimer with multiple moieties. Multifunctional dendrimers have been studied extensively and will certainly play a key role in upcoming medical devices [11,151,152]. That said, this approach has some caveats. Complete conversion of end groups is very difficult to achieve when sequentially adding moieties $[12,81,153,154]$. This leaves unreacted sites that need to be capped so that they do not react afterward and results in handful of active moieties (5/64 for example) statistically distributed on the surface of the dendrimer. In his 2012 review, Grinstaff made a point that the interest in dendrimers over other polymers is their monodispersity [11]. Therefore, statistically decorated dendrimers partially undermine this advantage. As depicted in Figure 4, several alternative architectures have been published where each dendron of a given dendrimer is fully decorated with a different species. Janus or bow-tie dendrimers were published before the advent of click chemistry [155], but it allowed greater flexibility around the concept. Extensive work by the Lee group and others produced a variety of structures. Among these, dendrimers of the same nature, but with different generations [59,156], same generation with different architectures [34,157], both [71,123,158] or different decorations [73] were reported over the last five years. The chemoselectivity and orthogonality of click reactions are instrumental in achieving these structures. In each case, monodispersity was maintained. A unique attempt at employing dendrimers to make molecular barcodes was published by the Hawker group [159]. CuAAC allowed them to fully decorate their dendrimer with different ratios of $(R)$ and $(S)$-groups. 


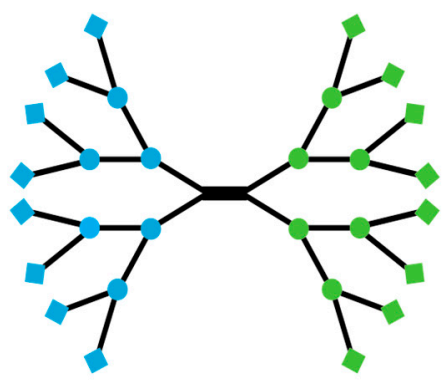

A) Janus

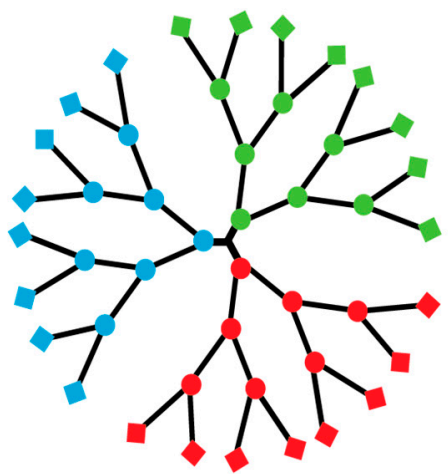

C) Three-faces (tri-orthogonal)

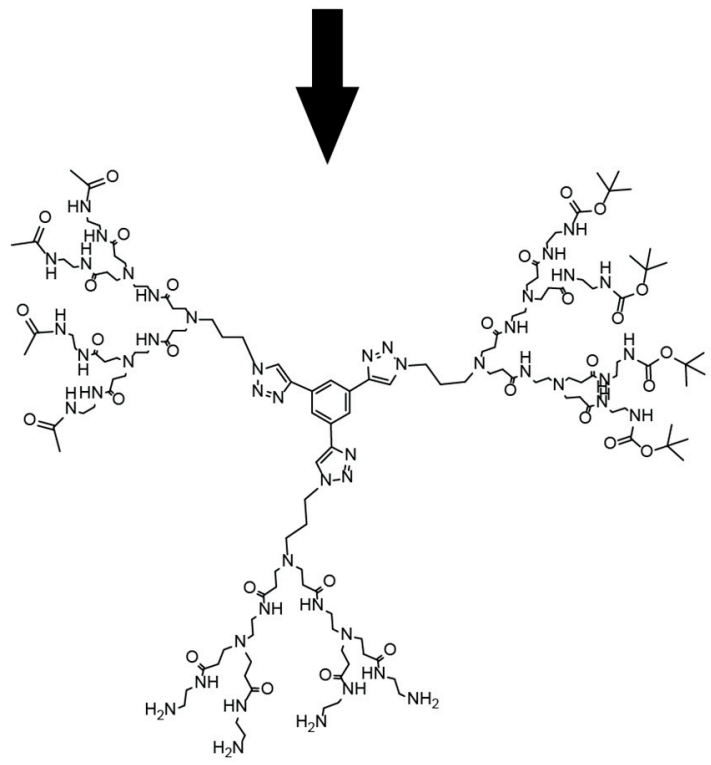

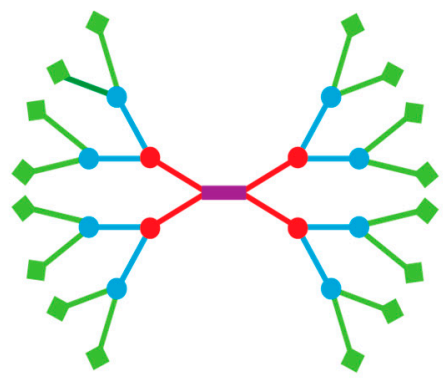

B) Onion peel

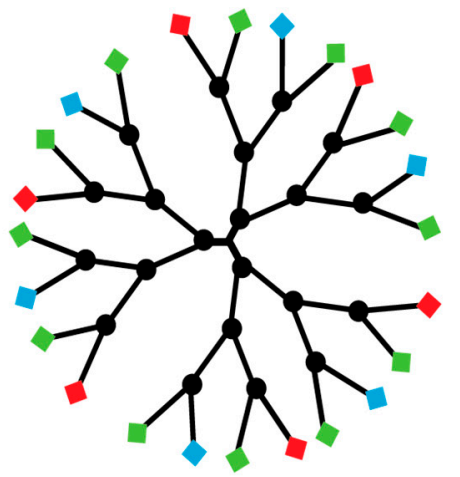

D) Three-faces (di-orthogonal)

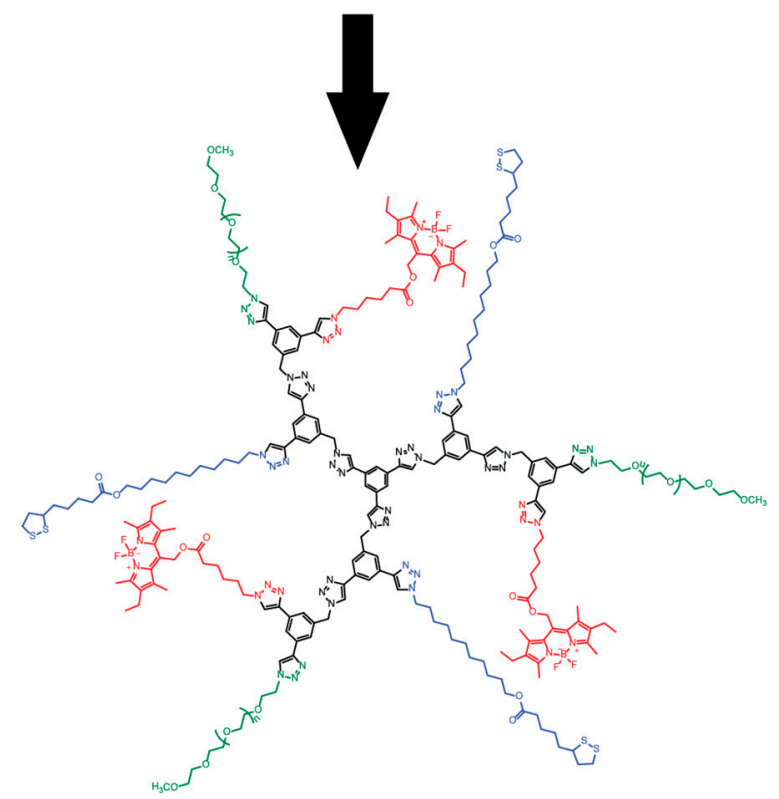

Figure 4. Complex dendritic architectures evolution from the pre-existing Janus (A) to the "onion peel" (B) and the three-faces strategies that rely on tri-orthogonality (C) or di-orthogonality (D).The structures of $\mathrm{C}$ and $\mathrm{D}$ are shown below to highlight how CuAAC was used only at the core for $\mathrm{C}$ and within the branches for $\mathrm{D}$.

Going back to the lab-on-a-molecule concept, there is a need for dendrimers bearing three or more well-defined faces. Orthogonality issues long barred the way to such structure, but from 2010 to 2012, several approaches were published on this concept, some featuring click reactions. Fukase et al., were the first ones to offer a monodisperse dendrimer bearing three different decorations [160] and 
Kakkar et al., expanded on the concept in 2011 [161]. They used an A(BC) approach where each branch in a branching point can be addressed independently, thus placing three types of decorating species while using a two-fold orthogonality. A few months later, we used the variety of available alkyne protecting groups as a source of three-fold orthogonality. It resulted in a controlled three-face PAMAM dendrimer [27]. As a side note, Weck [162] and Rudick [163] published syntheses of three-face dendrimers using non-click methods during the same period.

\subsubsection{The "Core-Shell-Surface" and the "Onion Peel" Strategies}

In 2011, the Müllen group described a layered dendrimer in which the core, the generations and the decorations are closely related, yet structurally different [164]. They dubbed this strategy "core-shell-surface" and used it to give the dendrimer complex optical behavior. Others in that field followed this idea $[165,166]$. In the biomedical area, CuAAC was used in the synthesis of a very large (47 kDa) polypeptide dendrimer by $\mathrm{Gu}[60]$. This dendrimer also has layered generations, each having a different structure. In 2014, the Roy group added to the concept by developing the "onion peel" strategy $[102,103]$. Here, each generation is not only structurally different from the others, but also relies on a different reaction. CUAAC, TEC/TYC and esterification were used in a single dendrimer. The potential advantages to this approach all revolve around the fine tuning of physico-chemical properties. Said properties will be the result of a balancing act between the layers. The idea was undoubtedly enabled by the orthogonality of click reactions and has already been picked up very recently by the Majoral group [124].

\subsubsection{Advances in Dendronized Polymer Synthesis}

Dendronized polymers are notoriously difficult to synthesize [167-169]. The wedge shape of the grafted dendrons prevents them from being close to each other along the main polymer chain. Many reactive sites are thus left untouched. Dynamic folding of the main chain in solution further affects the availability of said sites. This yields polymers with a very large polydispersity index. Alternatively, trying to polymerize dendrons through their focal point leads to a very low degree of polymerization. The third option is to grow the dendrons directly unto the polymer, but then growing steric hindrance can lower the purity of neighboring dendrons. Click chemistry alleviates some of these issues and teams now often opt for the first strategy, "clicking" premade dendrons unto the main chain. Most of these newly reported polymers used standard CuAAC [117,170-174], but others used DA [115,117-119,175] or TEC [176]. Here, the orthogonality and the efficient conversion of click reactions are both needed. Sanyal et al., harnessed the orthogonality of CuAAC and DA to assemble a dual-dendron dendronized polymer [117]. McElhanon also used CuAAC to add dendrons onto thermosensitive polymers built with click DA $[114,116]$. In a step-up of complexity, Sanyal and Rotello decorated a polymer with flavin units through CuAAC, which were further functionalized with dendrons through non-covalent bonds [175].

\subsubsection{Vesicles and Micelles}

The scientific community regularly produces complex macromolecules and supramolecular assemblies featuring dendrimers. Between 2010 and 2014, the Percec group, along with several collaborators, 
reported the creation of dendrimersomes [177,178]. Mimicking the behavior of phospholipids in cell membranes, amphiphilic dendrimers were synthesized. Their architecture and generations were varied, some even used TEC. It was observed that by varying the solvent, a plethora of self-assembled nanostructures ranging from disks to dendrimersomes could be obtained. The Roy group joined this multi-team endeavor and made amphiphilic glycodendrimers with CuAAC [179]. The resulting vesicles exhibit novel properties and trends, different from their dendritic constituents. As the authors explained, these assemblies could become the cornerstone of new biotechnologies featuring complex cell-like devices. Other groups have used click chemistry to assemble micelles from dendrimers. Thayumanavan used a complex asymmetric dendron to first create the micelle through self-assembly [180]. Then, UV light was used to crosslink the interior, trapping the guest molecule. Meanwhile, the Toth team used a long chain dendrimer decorated with peptides that self-assembled into a micelle that expressed the peptides at its surface [48].

\subsubsection{Degradable Dendrimers}

Self-immolative dendrimers occupy a growing niche in the scientific literature [181,182]. Born from the degradation studies of common dendrimers such as PAMAM and PPI, the field now actively seek to create dendrons made of weak covalent bonds. Programmable host delivery, tunable biodegradability and timed bio-release (like a spaceship shedding its rockets in stages) are example of applications. This is a stark departure from a common goal in material chemistry; to find sturdy links that can withstand the most conditions possible. Since CuAAC and TEC/TYC produce stable bonds, it may explain why click chemistry is very rarely used [183]. Nevertheless, the groups of Kakkar [113] and Hoogenboom [119] both employed rDA as the sensitive linkage. You used TEC to add a crosslinking ability to his immolating dendrimers [184].

\subsubsection{Other Complex Assemblies}

Entire dendrimers utilized as the building blocks of a larger system include the work of Holl [153], who used SPAAC to link together PAMAM dendrimers [82]. In a similar fashion, dendrimers can act as crosslink points to synthesize dense network polymers. CuAAC [185], TEC [104] and TYC [106] have all been used for this purpose in recent years. Malkoch et al., also combined CuAAC and TEC to fabricate a hydrogel centered on dendrimers [186]. Going in a different direction, Hamilton et al., reported the synthesis of oligoguanosines capped with clicked dendrons (Scheme 4) [91] These macromolecules self-assembled in a cube bearing a dendron at each corner. The structures were thermosensitive and combinatorial chemistry was performed. Nucleotide delivery and sensing could be achieved with this approach.

When coating a metallic surface or nanoparticles (NPs), most teams tether dendrons to the surface by the focal point. They do so to orient the end-groups outside, toward the solution. Inversely, researchers also use the termini as a multi-foot anchor [187,188]. In all cases, standard CuAAC was used without issue within these very complex systems. Two original articles concerning the synthesis of rotaxanes relied on CuAAC to install dendrons as end blockers $[33,189]$. Interestingly, the Lee group used a cucurbituril macrocycle that was not only part of the final rotaxane, but catalyzed CuAAC at the same time [33]. Finally, an original scaffold in which dendrimers line up on a DNA strand through strand 
association was reported by Gothelf et al. [146]. Half of the G4 PAMAMs were decorated with alkynes and the other half with azides. Once they were each associated at their respective places on a single strand bearing all the codes, CuAAC was performed to solder the dendrimers to each other. Linear and circular shapes were made using this method to demonstrate its ability to template large dendrimers.

(a)
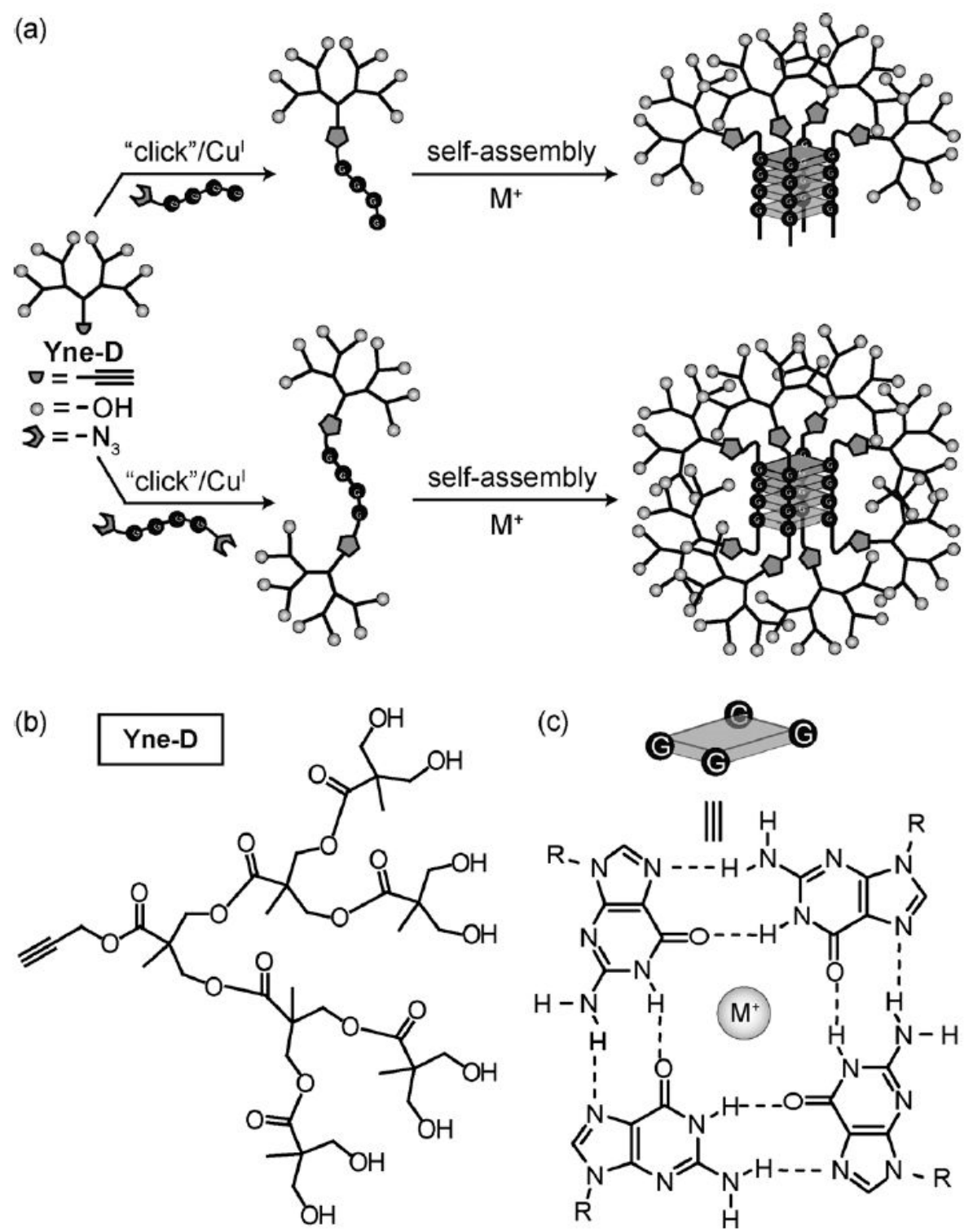

Scheme 4. Dendrons with an alkyne focal point are clicked on a nucleotide strand which ends bear azides. The global strategy where the Yne-D dendron is "clicked" on either a mono or di functionalized nucleotide strand is shown in (a). the structure of the Yne-D dendron is shown in (b) while (c) shows the detail of the nucleotide self-assembly around the metal ion. The resulting dendrimer self-assemble around a metal ion to form a cubic core with a total of four or eight dendrons. Reproduced with permission from Hamilton et al. [91].

\subsection{New Dendritic Architectures Featuring Click Chemistry}

Each year, several new dendritic architectures are published. Researchers either seek to adapt existing architectures to their specific needs or to overcome the synthetic problems that are common to all 
dendrimers. Nowadays, such problems are mainly purity at high generation, convenience and efficiency. The last two may seem frivolous, but they are important issues that still need to be overcome before new dendrimer-based devices can reach mass market applications [190,191]. This section focuses on the new architectures that employ a click reaction in at least one of the iterative step. Furthermore, click chemistry opened the possibility of modifying with a certain ease pre-existing architectures without major changes. This is why we choose to focus on novel strategies rather than specific branches.

Over the last five years, there has been a net increase in the number of dendrimers relying on either TEC or TYC. The two reactions were coupled to several other reactions such as Michael Addition [192], CuAAC [103,193], epoxy opening [194], esterification [192,195,196] and silane chemistry [197,198]. In 2009 and 2010, silane chemistry was used with either Grignard [199] or $\mathrm{NaBH}_{4}$ [200], demonstrating the sturdiness of the thioether. Soon after, Hawker and Malkoch published a combination of esterification, TEC and $\mathrm{CuAAC}$ in $\mathrm{AB}_{2} / \mathrm{CD}_{2}$ strategy [190]. They were able to quickly reach the 6th generation in a single day, much faster than other synthesis (Scheme 5).

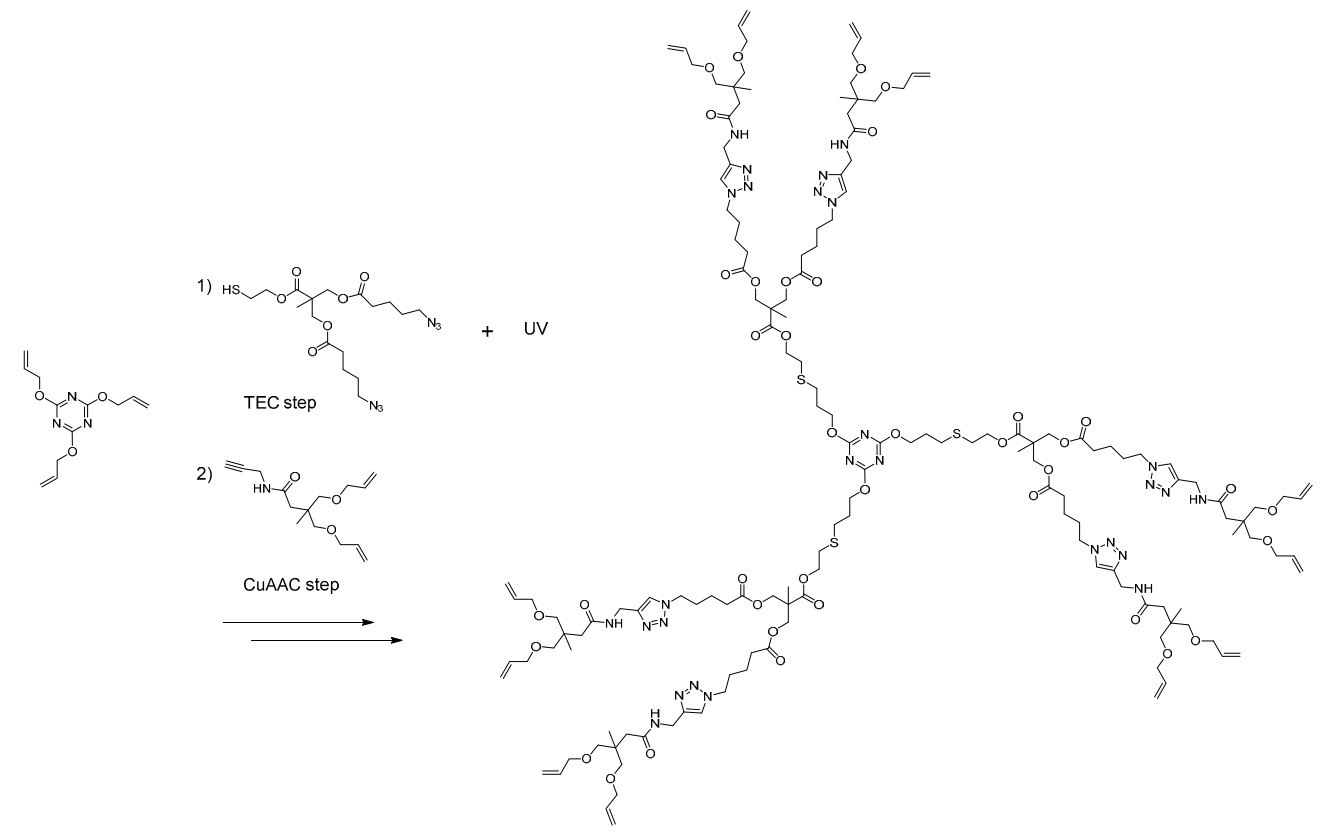

Scheme 5. The global strategy of Malkoch et al. Through careful synthesis of starting synthons, they were able to use CuAAC and TEC without any transformation. This allowed for a very convenient and fast divergent synthesis [190].

The polydispersity index rose from 1.02 to 1.21 between G4 to G5, signaling a critical point in steric hindrance at the periphery. Notably, they specifically chose not to perform chromatography at any step. Since then, Dondoni used it to make a glycodendrimer [193]. Afterward, Hawker published architectures, this time using TYC and epoxy opening [107,194]. An interesting feature of this dendrimer are the hydroxyl groups that are left free at each generation. As a proof-of-concept, they attached fluorophores to them. Since 2010, there have been some interesting cases of novel architectures involving CuAAC beside those mentioned in the paragraph above. First, Harriman et al., built a unique dendrimer made of porphyrines as the branching points in an $\mathrm{AB}_{3}$ fashion [90]. The core and each generation had its own metal core, leading to a complex electronic behavior. Second is the nitrone branching strategy presented by Junkers et al. [201] Here, a $\mathrm{AB} / \mathrm{CD}_{2}$ approach involving a seldom-used 
radical reaction combined with $\mathrm{CuAAC}$ afforded dendrimers up to G3. This is the only dendritic architecture we encountered that features N-O bonds. Third, Fokin [202] and Kakkar [203] both published similar carbon-rich scaffolds, using Sonogashira coupling on aromatic units to build their monomers. Finally, the Li group has published a series of dendrons and dendrimers built for non-linear optics purposes. Variations included internal decorations such as sulfate and nitro [204], but they could also swap the cores [205] and the terminal decorations [206], all thanks to the versatility of CuAAC. As discussed earlier, the groups of Brook and Morin published new methods of building dendrimers through highly activated alkynes (Scheme 6) [86,87]. These copper-free methods were developed with biomedical aims by purposefully avoiding metals from beginning to end. Early cytotoxicity results validate this approach [87]. Aspects of convenience and speed were also highlighted in these works.

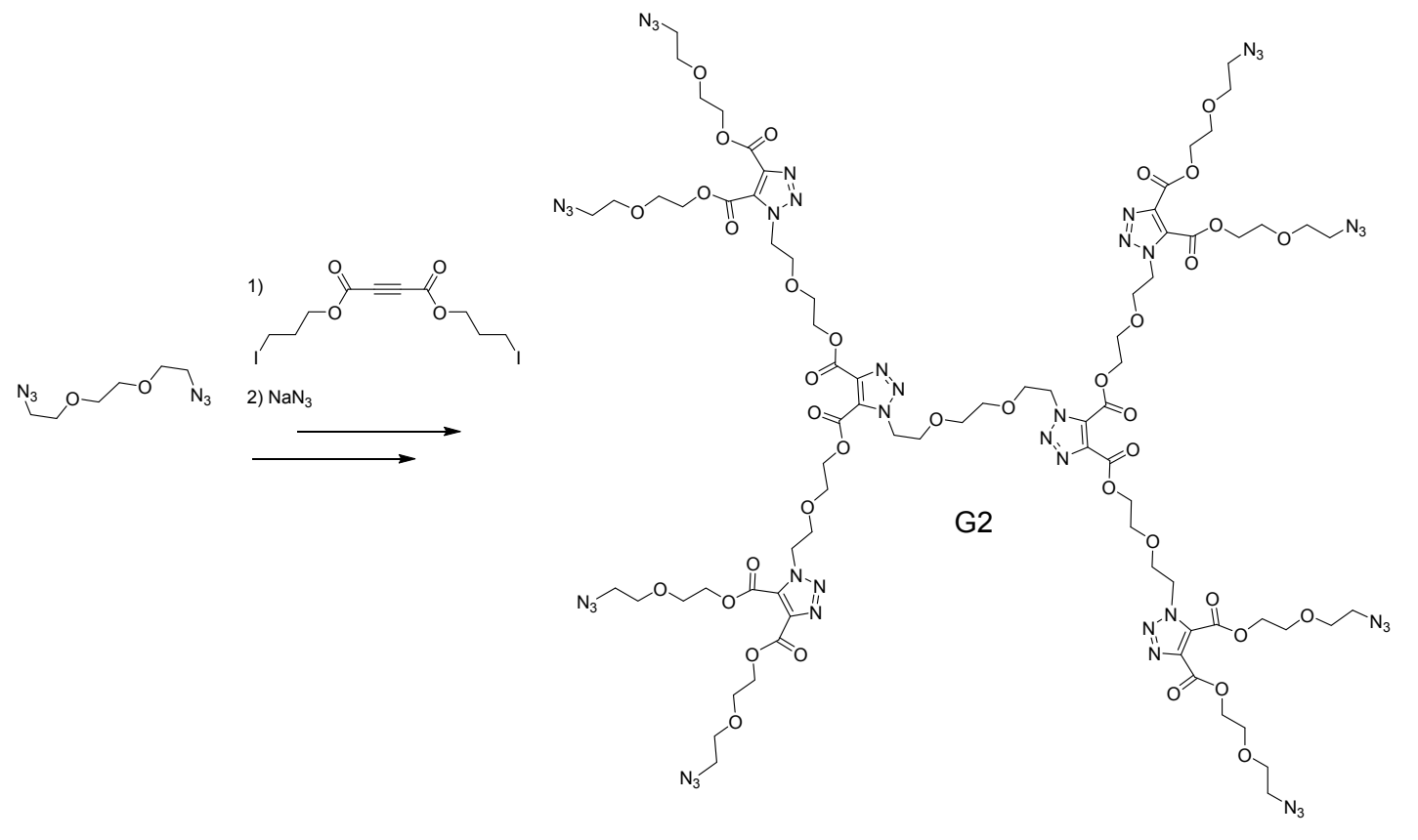

Scheme 6. A metal-free dendrimer assembled through the EWG-alkyne-azide strategy [87]. If the substrates are oils at room temperature, no solvent is needed and the reaction can be self-heated.

From time to time, the triazole group is sought after for its electronic properties. Astruc and others published a large body of work regarding dendrimers in which the triazole is conjugated to the decorating ferrocenyl [207-216] and cobalticinium [217]. This conjugation was found to have a positive influence on the redox ability of these dendrimers. Moreover, it was observed that the triazole can play an important role in catalysis and in the formation of Pd NPs. Another unique entry by Astruc et al., used the triazole as a covalent nucleation agent to grow gold nanoparticles [218]. The triazole can exhibit antifungal properties and is found in many synthetic drugs as well. These roles go beyond the scope of this review and have been detailed elsewhere [219,220].

\section{Conclusions}

In this focus review, we reported recent advances in click chemistry applied to dendrimer synthesis. Special attention was given to current and novel reaction conditions in CuAAC, TEC\TYC and DA. 
Recent applications of these three reactions were then reviewed. A few overarching trends could be identified. First, while CuAAC remains the most used of all click reactions, it is now losing ground to the other ones and to its copper-free variants. SPAAC is now commonly used to decorate dendrimers and a few novel architectures relying on highly activated alkynes were recently published. Copper removal continues to be a concern in dendrimer synthesis, but there is now a wide array of methods available. The second major trend is that between Kakkar's 2010 review and now, TEC went from "novel" to "well-established". The combination of all the new dendritic architectures using TEC or TYC constitute a useful body of knowledge. It will be interesting to see which, if any, will come out as the most popular. Asking this question, though, might quickly become irrelevant as we see a shift from the type of branches to rather a given set of iterative reaction that are not tied to a specific monomer. Going even further, the "onion peel" strategy showcased how click chemistry enables a high degree of customization of dendritic architectures. The third trend our survey highlighted is how click chemistry is now a philosophy that extend beyond its own reaction. Case in point, the Michael Addition, a reaction that predates click, is now described as being click. Within the scope of dendrimer synthesis, we noted a deconstruction of the paradigm with the catalytic and the environmental friendliness set aside when needed. Reactions are sometime seen as having click-like characteristics [127]. As a final note, our survey picked many articles about hyperbranched polymers arguing that dendrimer synthesis is too difficult. This next-door-neighbor look offers a good indication that the field still needs to strive for greater ease. Click chemistry is instrumental in tackling these issues. As reported here, great progress has been accomplished in a short time.

\section{Acknowledgments}

Our research group is supported by grants from the NSERC (Québec, QC, Canada), FQRNT (Québec, QC, Canada), CQMF (Québec, QC, Canada).

\section{Conflicts of Interest}

The authors declare no conflict of interest.

\section{References and Notes}

1. Kolb, H.C.; Finn, M.G.; Sharpless, K.B. Click Chemistry: Diverse Chemical Function from a Few Good Reactions. Angew. Chem. Int. Ed. 2001, 40, 2004-2021.

2. Wu, P.; Feldman, A.K.; Nugent, A.K.; Hawker, C.J.; Scheel, A.; Voit, B.; Pyun, J.; Fréchet, J.M.J.; Sharpless, K.B.; Fokin, V.V. Efficiency and Fidelity in a Click-Chemistry Route to Triazole Dendrimers by the Copper(I)-Catalyzed Ligation of Azides and Alkynes. Angew. Chem. Int. Ed. 2004, 43, 3928-3932.

3. Franc, G.; Kakkar, A.K. "Click" methodologies: Efficient, simple and greener routes to design dendrimers. Chem. Soc. Rev. 2010, 39, 1536-1544.

4. Gao, C.; Yan, D. Hyperbranched polymers: From synthesis to applications. Prog. Polym. Sci. 2004, 29, 183-275.

5. Qin, A.; Lam, J.W.Y.; Tang, B.Z. Click polymerization. Chem. Soc. Rev. 2010, 39, 2522-2544. 
6. Hadjichristidis, N.; Pitsikalis, M.; Pispas, S.; Iatrou, H. Polymers with Complex Architecture by Living Anionic Polymerization. Chem. Rev. 2001, 101, 3747-3792.

7. Tomalia, D.A.; Baker, H.; Dewald, J.; Hall, M.; Kallos, G.; Martin, S.; Roeck, J.; Ryder, J.; Smith, P. A New Class of Polymers: Starburst-Dendritic Macromolecules. Polym. J. 1985, 17, 117-132.

8. Klajnert, B.; Peng, L.; Cena, V. Dendrimers in Biomedical Applications; Royal Society of Chemistry: Cambridge, UK, 2013; p. 204.

9. Tomalia, D.A.; Fréchet, J.M.J. Dendrimers and Other Dendritic Polymers; John Wiley \& Sons: New York, NY, USA, 2002.

10. Shcharbin, D.; Klajnert, B.; Bryszewska, M. Practical Guide to Studying Dendrimers, 1st ed.; iSmithers Rapra Publishing: Shawbury, UK, 2010.

11. Mintzer, M.A.; Grinstaff, M.W. Biomedical applications of dendrimers: a tutorial. Chem. Soc. Rev. 2011, 40, 173-190.

12. McNerny, D.Q.; Mullen, D.G.; Majoros, I.J.; Banaszak Holl, M.M.; Baker, J.R. Dendrimer Synthesis and Functionalization by Click Chemistry for Biomedical Applications. In Click Chemistry for Biotechnology and Materials Science; John Wiley \& Sons: New York City, NY, USA, 2009; pp. 177-193.

13. Cheng, Y.; Zhao, L.; Li, Y.; Xu, T. Design of biocompatible dendrimers for cancer diagnosis and therapy: Current status and future perspectives. Chem. Soc. Rev. 2011, 40, 2673-2703.

14. Balzani, V.; Campagna, S.; Denti, G.; Juris, A.; Serroni, S.; Venturi, M. Designing Dendrimers Based on Transition-Metal Complexes. Light-Harvesting Properties and Predetermined Redox Patterns. Acc. Chem. Res. 1998, 31, 26-34.

15. Adronov, A.; Frechet, J.M.J. Light-harvesting dendrimers. Chem. Commun. 2000, 1701-1710.

16. Wang, D.; Astruc, D. Dendritic catalysis - Basic concepts and recent trends. Coord. Chem. Rev. 2013, 257, 2317-2334.

17. McCarthy, T.D.; Karellas, P.; Henderson, S.A.; Giannis, M.; O’Keefe, D.F.; Heery, G.; Paull, J.R.A.; Matthews, B.R.; Holan, G. Dendrimers as Drugs: Discovery and Preclinical and Clinical Development of Dendrimer-Based Microbicides for HIV and STI Prevention. Mol. Pharm. 2005, 2, 312-318.

18. With a known conversiosn percentage for a given reaction, one can obtain the percentage of "perfect" dendrimer for a given generation (divergent method). This simplified formula does not account for purification steps or the de Gennes packing effects. First, the total number of time the reaction has been done (Y) must be calculated. For this, we sum the number of surface groups given by the formula of Tomalia et al., $\mathrm{Y}=\sum_{0}^{\mathrm{G}} \mathrm{N}_{\mathrm{c}} \mathrm{N}_{\mathrm{b}} \mathrm{G}$, where $\mathrm{N}_{\mathrm{c}}$ is the core multiplicity, $\mathrm{N}_{\mathrm{b}}$ is the branch cell multiplicity and $\mathrm{G}$ stands for the generation. From this, with a known conversion rate $(\mathrm{m})$, one can calculate the percentage of defect-free dendrimer $(\mathrm{x})$ with formula 2: confirm the format $\mathrm{x}=\mathrm{m}^{\mathrm{Y}}$. As an example, for a G6 PAMAM, with a $\mathrm{m}$ of $95 \%$, we obtain $2 \times 10^{-4} \%$ of the desired dendrimer, while a $99 \%$ conversion gives $8 \%$. Details of this work are available upon request.

19. Xi, W.; Scott, T.F.; Kloxin, C.J.; Bowman, C.N. Click Chemistry in Materials Science. Adv. Funct. Mater. 2014, 24, 2572-2590. 
20. Iha, R.K.; Wooley, K.L.; Nyström, A.M.; Burke, D.J.; Kade, M.J.; Hawker, C.J. Applications of Orthogonal "Click" Chemistries in the Synthesis of Functional Soft Materials. Chem. Rev. 2009, 109, 5620-5686.

21. Such, G.K.; Johnston, A.P.R.; Liang, K.; Caruso, F. Synthesis and functionalization of nanoengineered materials using click chemistry. Prog. Polym. Sci. 2012, 37, 985-1003.

22. Rostovtsev, V.V.; Green, L.G.; Fokin, V.V.; Sharpless, K.B. A Stepwise Huisgen Cycloaddition Process: Copper(I)-Catalyzed Regioselective "Ligation" of Azides and Terminal Alkynes. Angew. Chem. Int. Ed. 2002, 41, 2596-2599.

23. Spiteri, C.; Moses, J.E. Copper-Catalyzed Azide-Alkyne Cycloaddition: Regioselective Synthesis of 1,4,5-Trisubstituted 1,2,3-Triazoles. Angew. Chem. Int. Ed. 2010, 49, 31-33.

24. Bock, V.D.; Hiemstra, H.; van Maarseveen, J.H. CuI-Catalyzed Alkyne-Azide "Click" Cycloadditions from a Mechanistic and Synthetic Perspective. Eur. J. Org. Chem. 2006, 2006, 51-68.

25. Berg, R.; Straub, B.F. Advancements in the mechanistic understanding of the copper-catalyzed azide-alkyne cycloaddition. Beilstein J. Org. Chem. 2013, 9, 2715-2750.

26. Hein, J.E.; Fokin, V.V. Copper-catalyzed azide-alkyne cycloaddition (CuAAC) and beyond: New reactivity of copper(I) acetylides. Chem. Soc. Rev. 2010, 39, 1302-1315.

27. Arseneault, M.; Dufour, P.; Levesque, I.; Morin, J.-F. Synthesis of a controlled three-faced PAMAM particle. Polym. Chem. 2011, 2, 2293-2298.

28. Han, S.C.; Kim, J.H.; Lee, J.W. Convergent synthesis of PAMAM dendrimers containing tetra(ethylene oxide) at core using click chemistry. Bull. Korean Chem. Soc. 2012, 33, 3501-3504.

29. Papadopoulos, A.; Shiao, T.C.; Roy, R. Diazo transfer and Click chemistry in the solid phase syntheses of lysine-based glycodendrimers as antagonists against Escherichia coli FimH. Mol. Pharm. 2012, 9, 394-403.

30. Yim, C.-B.; Dijkgraaf, I.; Merkx, R.; Versluis, C.; Eek, A.; Mulder, G.E.; Rijkers, D.T.S.; Boerman, O.C.; Liskamp, R.M.J. Synthesis of DOTA-Conjugated Multimeric [Tyr3]Octreotide Peptides via a Combination of $\mathrm{Cu}(\mathrm{I})$-Catalyzed "Click" Cycloaddition and Thio Acid/Sulfonyl Azide "Sulfo-Click" Amidation and Their in Vivo Evaluation. J. Med. Chem. 2010, 53, 3944-3953.

31. Gatard, S.; Liang, L.; Salmon, L.; Ruiz, J.; Astruc, D.; Bouquillon, S. Water-soluble glycodendrimers: Synthesis and stabilization of catalytically active $\mathrm{Pd}$ and $\mathrm{Pt}$ nanoparticles. Tetrahedron Lett. 2011, 52, 1842-1846.

32. Elias, D.R.; Cheng, Z.; Tsourkas, A. An Intein-Mediated Site-Specific Click Conjugation Strategy for Improved Tumor Targeting of Nanoparticle Systems. Small 2010, 6, 2460-2468.

33. Han, S.C.; Yoon, J.; Oh, J.; Lee, J.W. Synthesis of [3]-rotaxane dendrimers by host-mediated click chemistry. Bull. Korean Chem. Soc. 2011, 32, 3809-3812.

34. Han, S.C.; Choi, I.-H.; Jin, S.-H.; Lee, J.W. Efficient Synthesis of Carbazole Core Diblock Dendrimer by Double Click Chemistry. Mol. Cryst. Liquid Cryst. 2014, 599, 86-95.

35. Rodionov, V.O.; Fokin, V.V.; Finn, M.G. Mechanism of the Ligand-Free CuI-Catalyzed Azide-Alkyne Cycloaddition Reaction. Angew. Chem. Int. Ed. 2005, 44, 2210-2215.

36. Siemsen, P.; Livingston, R.C.; Diederich, F. Acetylenic Coupling: A Powerful Tool in Molecular Construction. Angew. Chem. Int. Ed. 2000, 39, 2632-2657.

37. Meldal, M.; Tornøe, C.W. Cu-Catalyzed Azide-Alkyne Cycloaddition. Chem. Rev. 2008, 108, 2952-3015. 
38. Wu, W.; Yu, G.; Liu, Y.; Ye, C.; Qin, J.; Li, Z. Using two simple methods of Ar-ArF self-assembly and isolation chromophores to further improve the comprehensive performance of NLO dendrimers. Chem. Eur. J. 2013, 19, 630-641.

39. Chamorro, C.; Boerman, M.A.; Arnusch, C.J.; Breukink, E.; Pieters, R.J. Enhancing membrane disruption by targeting and multivalent presentation of antimicrobial peptides. Biochim. Biophys. Acta 2012, 1818, 2171-2174.

40. Ledin, P.A.; Friscourt, F.; Guo, J.; Boons, G.-J. Convergent Assembly and Surface Modification of Multifunctional Dendrimers by Three Consecutive Click Reactions. Chem. Eur. J. 2011, 17, 839-846.

41. Liu, T.; Oukacine, F.; Collet, H.; Commeyras, A.; Vial, L.; Cottet, H. Monitoring surface functionalization of dendrigraft poly-1-lysines via click chemistry by capillary electrophoresis and Taylor dispersion analysis. J. Chromatogr. A 2013, 1273, 111-116.

42. Lee, J.W.; Han, S.C.; Yun, S.-H.; Jin, S.-H. Convergent synthesis of carbazole core PAMAM dendrimer via click chemistry. Bull. Korean Chem. Soc. 2013, 34, 971-974.

43. Kainz, Q.M.; Schaetz, A.; Zoepfl, A.; Stark, W.J.; Reiser, O. Combined Covalent and Noncovalent Functionalization of Nanomagnetic Carbon Surfaces with Dendrimers and BODIPY Fluorescent Dye. Chem. Mater. 2011, 23, 3606-3613.

44. Haridas, V.; Sharma, Y.K.; Sahu, S.; Verma, R.P.; Sadanandan, S.; Kacheshwar, B.G. Designer peptide dendrimers using click reaction. Tetrahedron 2011, 67, 1873-1884.

45. Gupta, S.; Schade, B.; Kumar, S.; Boettcher, C.; Sharma, S.K.; Haag, R. Non-ionic dendronized multiamphiphilic polymers as nanocarriers for biomedical applications. Small 2013, 9, 894-904.

46. Li, Z.A.; Wu, W.; Li, Q.; Yu, G.; Xiao, L.; Liu, Y.; Ye, C.; Qin, J.; Li, Z. High-Generation Second-Order Nonlinear Optical (NLO) Dendrimers: Convenient Synthesis by Click Chemistry and the Increasing Trend of NLO Effects. Angew. Chem. Int. Ed. 2010, 49, 2763-2767.

47. Peschko, K.; Schade, A.; Vollrath, S.B. L.; Schwarz, U.; Luy, B.; Muhle-Goll, C.; Weis, P.; Braese, S. Dendrimer-Type Peptoid-Decorated Hexaphenylxylenes and Tetraphenylmethanes: Synthesis and Structure in Solution and in the Gas Phase. Chem. Eur. J. 2014, 20, 16273-16278.

48. Skwarczynski, M.; Zaman, M.; Urbani, C.N.; Lin, I.C.; Jia, Z.; Batzloff, M.R.; Good, M.F.; Monteiro, M.J.; Toth, I. Polyacrylate Dendrimer Nanoparticles: A Self-Adjuvanting Vaccine Delivery System. Angew. Chem. Int. Ed. 2010, 49, 5742-5745.

49. Pourceau, G.; Meyer, A.; Chevolot, Y.; Souteyrand, E.; Vasseur, J.-J.; Morvan, F. Oligonucleotide Carbohydrate-Centered Galactosyl Cluster Conjugates Synthesized by Click and Phosphoramidite Chemistries. Bioconjugate Chem. 2010, 21, 1520-1529.

50. Lal, S.; Díez-González, S. [CuBr(PPh3)3] for Azide-Alkyne Cycloaddition Reactions under Strict Click Conditions. J. Org. Chem. 2011, 76, 2367-2373.

51. Worrell, B.T.; Malik, J.A.; Fokin, V.V. Direct Evidence of a Dinuclear Copper Intermediate in $\mathrm{Cu}(\mathrm{I})$-Catalyzed Azide-Alkyne Cycloadditions. Science 2013, 340, 457-460.

52. Chen, H.-B.; Abeyrathna, N.; Liao, Y. Alkyne-azide cycloaddition catalyzed by a dinuclear copper(I) complex. Tetrahedron Lett. 2014, 55, 6575-6576.

53. Iacobucci, C.; Reale, S.; Gal, J.-F.; de Angelis, F. Dinuclear Copper Intermediates in Copper(I)-Catalyzed Azide-Alkyne Cycloaddition Directly Observed by Electrospray Ionization Mass Spectrometry. Angew. Chem. Int. Ed. 2015, 54, 3065-3068. 
54. Liang, L.; Ruiz, J.; Astruc, D. The Efficient Copper(I) (Hexabenzyl)tren Catalyst and Dendritic Analogues for Green "Click" Reactions between Azides and Alkynes in Organic Solvent and in Water: Positive Dendritic Effects and Monometallic Mechanism. Adv. Synth. Catal. 2011, 353, 3434-3450.

55. Shao, C.; Wang, X.; Xu, J.; Zhao, J.; Zhang, Q.; Hu, Y. Carboxylic Acid-Promoted Copper(I)-Catalyzed Azide-Alkyne Cycloaddition. J. Org. Chem. 2010, 75, 7002-7005.

56. Soto-Castro, D.; Magana-Vergara, N.E.; Farfan, N.; Santillan, R. Synthesis of steroidal dendrimers modified by "click" chemistry with PAMAM dendrons as unimolecular micelles. Tetrahedron Lett. 2014, 55, 1014-1019.

57. Huisgen, R. 1,3-Dipolar Cycloadditions. Past and Future. Angew. Chem. Int. Ed. 1963, 2, 565-598.

58. Boren, B.C.; Narayan, S.; Rasmussen, L.K.; Zhang, L.; Zhao, H.; Lin, Z.; Jia, G.; Fokin, V.V. Ruthenium-Catalyzed Azide-Alkyne Cycloaddition: Scope and Mechanism. J. Am. Chem. Soc. 2008, 130, 8923-8930.

59. Han, S.C.; Kwak, S.H.; Jin, S.-H.; Lee, J.W. Synthesis of unsymmetrical Frechet-type dendrimers via double click chemistry. Bull. Korean Chem. Soc. 2012, 33, 1393-1396.

60. Luo, K.; Li, C.; Li, L.; She, W.; Wang, G.; Gu, Z. Arginine functionalized peptide dendrimers as potential gene delivery vehicles. Biomaterials 2012, 33, 4917-4927.

61. Kappe, C.O.; Van der Eycken, E. Click chemistry under non-classical reaction conditions. Chem. Soc. Rev. 2010, 39, 1280-1290.

62. Lee, C.Y.; Held, R.; Sharma, A.; Baral, R.; Nanah, C.; Dumas, D.; Jenkins, S.; Upadhaya, S.; Du, W. Copper-Granule-Catalyzed Microwave-Assisted Click Synthesis of Polyphenol Dendrimers. J. Org. Chem. 2013, 78, 11221-11228.

63. Barge, A.; Caporaso, M.; Cravotto, G.; Martina, K.; Tosco, P.; Aime, S.; Carrera, C.; Gianolio, E.; Pariani, G.; Corpillo, D. Design and Synthesis of a $\gamma 1 \beta 8$-Cyclodextrin Oligomer: A New Platform with Potential Application as a Dendrimeric Multi-carrier. Chem. Eur. J. 2013, 19, 12086-12092.

64. Cendret, V.; Francois-Heude, M.; Mendez-Ardoy, A.; Moreau, V.; Garcia Fernandez, J.M.; Djedaini-Pilard, F. Design and synthesis of a "click" high-mannose oligosaccharide mimic emulating Man8 binding affinity towards Con A. Chem. Commun. 2012, 48, 3733-3735.

65. Ottaviani, M.F.; Bossmann, S.; Turro, N.J.; Tomalia, D.A. Characterization of starburst dendrimers by the EPR technique. 1. Copper complexes in water solution. J. Am. Chem. Soc. 1994, 116, 661-671.

66. Diallo, M.S.; Balogh, L.; Shafagati, A.; Johnson, J.H.; Goddard, W.A.; Tomalia, D.A. Poly(amidoamine) Dendrimers: A New Class of High Capacity Chelating Agents for Cu(II) Ions. Environ. Sci. Technol. 1999, 33, 820-824.

67. Wan, X.J.; Xu, J.; Liu, S.Y. Facile synthesis of dendrimer-like star-branched poly(isopropylacrylamide) via combination of click chemistry and atom transfer radical polymerization. Sci. China: Chem. 2010, 53, 2520-2527.

68. Brewer, G.J. Copper toxicity in the general population. Clin. Neurophysiol. 2009, 121, 459-460.

69. Tan, S.S.; Kim, S.J.; Kool, E.T. Differentiating between Fluorescence-Quenching Metal Ions with Polyfluorophore Sensors Built on a DNA Backbone. J. Am. Chem. Soc. 2011, 133, 2664-2671.

70. Lang, H; Chandler, B.D. Dendrimer templates for supported nanoparticle catalysts. In Nanotechnology in Catalysis; Springer-Verlag: New York, NY, USA, 2007; Volume 3, pp. 91-113. 
71. Fedeli, E.; Lancelot, A.; Serrano, J.L.; Calvo, P.; Sierra, T. Self-assembling amphiphilic Janus dendrimers: mesomorphic properties and aggregation in water. New J. Chem. 2015, 39, 1960-1967

72. Kecskes, A.; Tosh, D.K.; Wei, Q.; Gao, Z.-G.; Jacobson, K.A. GPCR Ligand Dendrimer (GLiDe) Conjugates: Adenosine Receptor Interactions of a Series of Multivalent Xanthine Antagonists. Bioconjugate Chem. 2011, 22, 1115-1127.

73. Gao, C.; Liu, M.; Lu, S.; Zhang, X.; Chen, Y. Synthesis and self-assembly of PAMAM/PAA Janus dendrimers. Mater. Res. Express 2014, 1, 15005-150017.

74. Deraedt, C.; Pinaud, N.; Astruc, D. Recyclable Catalytic Dendrimer Nanoreactor for Part-Per-Million CuI Catalysis of "Click" Chemistry in Water. J. Am. Chem. Soc. 2014, 136, 12092-12098.

75. Lammens, M.; Skey, J.; Wallyn, S.; O’Reilly, R.; Du Prez, F. Polymeric ligands as homogeneous, reusable catalyst systems for copper assisted click chemistry. Chem. Commun. 2010, 46, 8719-8721.

76. Gordon, C.G.; Mackey, J.L.; Jewett, J.C.; Sletten, E.M.; Houk, K.N.; Bertozzi, C.R. Reactivity of Biarylazacyclooctynones in Copper-Free Click Chemistry. J. Am. Chem. Soc. 2012, 134, 9199-9208.

77. Baskin, J.M.; Prescher, J.A.; Laughlin, S.T.; Agard, N.J.; Chang, P.V.; Miller, I.A.; Lo, A.; Codelli, J.A.; Bertozzi, C.R. Copper-free click chemistry for dynamic in vivo imaging. Proc. Natl. Acad. Sci. USA 2007, 104, 16793-16797.

78. Van Dongen, M.A.; Rattan, R.; Silpe, J.; Dougherty, C.; Michmerhuizen, N.L.; van Winkle, M.; Huang, B.; Choi, S.K.; Sinniah, K.; Orr, B.G.; Banaszak Holl, M.M. Poly(amidoamine) Dendrimer-Methotrexate Conjugates: The Mechanism of Interaction with Folate Binding Protein. Mol. Pharm. 2014, 11, 4049-4058.

79. Xu, L.; Zolotarskaya, O.Y.; Yeudall, W.A.; Yang, H. Click Hybridization of Immune Cells and Polyamidoamine Dendrimers. Adv. Healthcare Mater. 2014, 3, 1430-1438.

80. Ornelas, C.; Broichhagen, J.; Weck, M. Strain-Promoted Alkyne Azide Cycloaddition for the Functionalization of Poly(amide)-Based Dendrons and Dendrimers. J. Am. Chem. Soc. 2010, 132, 3923-3931.

81. Zong, H.; Goonewardena, S.N.; Chang, H.-N.; Otis, J.B.; Baker, J.R., Jr. Sequential and parallel dual labeling of nanoparticles using click chemistry. Bioorg. Med. Chem. 2014, 22, 6288-6296.

82. Van Dongen, M.A.; Vaidyanathan, S.; Banaszak Holl, M.M. PAMAM dendrimers as quantized building blocks for novel nanostructures. Soft Matter 2013, 9, 11188-11196.

83. Lee, C.Y.; Nanah, C.N.; Held, R.A.; Clark, A.R.; Huynh, U.G.T.; Maraskine, M.C.; Uzarski, R.L.; McCracken, J.; Sharma, A. Effect of electron donating groups on polyphenol-based antioxidant dendrimers. Biochimie 2015, 111, 125-134.

84. Chenoweth, K.; Chenoweth, D.; Goddard Iii, W.A. Cyclooctyne-based reagents for uncatalyzed click chemistry: A computational survey. Org. Biomol. Chem. 2009, 7, 5255-5258.

85. Heyl, D.; Rikowski, E.; Hoffmann, R.C.; Schneider, J.J.; Fessner, W.-D. A "Clickable” Hybrid Nanocluster of Cubic Symmetry. Chem. Eur. J. 2010, 16, 5544-5548.

86. Gonzaga, F.; Sadowski, L.P.; Rambarran, T.; Grande, J.; Adronov, A.; Brook, M.A. Highly efficient divergent synthesis of dendrimers via metal-free "click" chemistry. J. Polym. Sci. Part. A: Polym. Chem. 2013, 51, 1272-1277.

87. Arseneault, M.; Levesque, I.; Morin, J.-F. Efficient and Rapid Divergent Synthesis of Ethylene Oxide-Containing Dendrimers through Catalyst-Free Click Chemistry. Macromolecules 2012, 45, 3687-3694. 
88. Kowalczyk, W.; Mascaraque, A.; Sanchez-Navarro, M.; Rojo, J.; Andreu, D. Convergent Synthesis of Glycodendro-peptides by Click Chemistry Approaches. Eur. J. Org. Chem. 2012, 2012, 4565-4573.

89. Rajakumar, P.; Thirunarayanan, A.; Raja, S.; Ganesan, S.; Maruthamuthu, P. Photophysical properties and dye-sensitized solar cell studies on thiadiazole-triazole-chalcone dendrimers. Tetrahedron Lett. 2012, 53, 1139-1143.

90. Le Pleux, L.; Pellegrin, Y.; Blart, E.; Odobel, F.; Harriman, A. Long-Lived, Charge-Shift States in Heterometallic, Porphyrin-Based Dendrimers Formed via Click Chemistry. J. Phys. Chem. A 2011, 115, 5069-5080.

91. Ghosh, P.S.; Hamilton, A.D. Supramolecular Dendrimers: Convenient Synthesis by Programmed Self-Assembly and Tunable Thermoresponsivity. Chem. Eur. J. 2012, 18, 2361-2365.

92. Hoogenboom, R. Thiol-Yne Chemistry: A Powerful Tool for Creating Highly Functional Materials. Angew. Chem. Int. Ed. 2010, 49, 3415-3417.

93. Lowe, A.B. Thiol-ene "click" reactions and recent applications in polymer and materials synthesis. Polym. Chem. 2010, 1, 17-36.

94. Lowe, A.B.; Harvison, M.A. Thiol-Based "Click" Chemistries in Polymer: Synthesis and Modification. Aust. J. Chem. 2010, 63, 1251-1266.

95. Hoyle, C.E.; Lee, T.Y.; Roper, T. Thiol-enes: Chemistry of the past with promise for the future. J. Polym. Sci. Part A: Polym. Chem. 2004, 42, 5301-5338.

96. Scanlan E.M.; Corcé V.; Malone, A. Synthetic Applications of Intramolecular Thiol-Ene "Click" Reaction. Molecules 2014, 19, 19137-19151.

97. Hoyle, C.E.; Bowman, C.N. Thiol-Ene Click Chemistry. Angew. Chem. Int. Ed. 2010, 49, 1540-1573.

98. Xu, Y.; Xiong, X.; Cai, L.; Tang, Z.; Ye, Z. Thiol-ene click chemistry. Huaxue Jinzhan 2012, 24, 385-394.

99. Sapkale, P.; Sahu, M.; Chaudhari, M.; Patil, P.R. Trends of click synthesis: a review. Int. J. Pharm. Pharm. Sci. 2014, 6, 99-103.

100. Lowe, A.B. Thiol-ene "click" reactions and recent applications in polymer and materials synthesis: a first update. Polym. Chem. 2014, 5, 4820-4870.

101. Lo Conte, M.; Pacifico, S.; Chambery, A.; Marra, A.; Dondoni, A. Photoinduced Addition of Glycosyl Thiols to Alkynyl Peptides: Use of Free-Radical Thiol-Yne Coupling for Post-Translational Double-Glycosylation of Peptides. J. Org. Chem. 2010, 75, 4644-4647.

102. Sharma, R.; Kottari, N.; Chabre, Y.M.; Abbassi, L.; Shiao, T.C.; Roy, R. A highly versatile convergent/divergent "onion peel" synthetic strategy toward potent multivalent glycodendrimers. Chem. Commun. 2014, 50, 13300-13303.

103. Sharma, R.; Naresh, K.; Chabre, Y.M.; Rej, R.; Saadeh, N.K.; Roy, R. “Onion peel” dendrimers: A straightforward synthetic approach towards highly diversified architectures. Polym. Chem. 2014, 5, 4321-4331.

104. Chatani, S.; Podgórski, M.; Wang, C.; Bowman, C.N. Facile and Efficient Synthesis of Dendrimers and One-Pot Preparation of Dendritic-Linear Polymer Conjugates via a Single Chemistry: Utilization of Kinetically Selective Thiol-Michael Addition Reactions. Macromolecules 2014, 47, 4894-4900.

105. Lowe, A.B.; Hoyle, C.E.; Bowman, C.N. Thiol-yne click chemistry: A powerful and versatile methodology for materials synthesis. J. Mater. Chem. 2010, 20, 4745-4750. 
106. Cervera-Procas, R.; Sanchez-Somolinos, C.; Serrano, J.L.; Omenat, A. A Polymer Network Prepared by the Thiol-yne Photocrosslinking of a Liquid Crystalline Dendrimer. Macromol. Rapid Commun. 2013, 34, 498-503.

107. Amir, R.J.; Albertazzi, L.; Willis, J.; Khan, A.; Kang, T.; Hawker, C.J. Multifunctional Trackable Dendritic Scaffolds and Delivery Agents. Angew. Chem. Int. Ed. 2011, 50, 3425-3429.

108. Gingras, M.; Chabre, Y.M.; Roy, M.; Roy, R. How do multivalent glycodendrimers benefit from sulfur chemistry? Chem. Soc. Rev. 2013, 42, 4823-4841.

109. Tasdelen, M.A. Diels-Alder "click" reactions: recent applications in polymer and material science. Polym. Chem. 2011, 2, 2133-2145.

110. Morgenroth, F.; Müllen, K. Dendritic and hyperbranched polyphenylenes via a simple Diels-Alder route. Tetrahedron 1997, 53, 15349-15366.

111. Geyer, F.L.; Rode, A.; Bunz, U.H.F. Fourfold Diels-Alder Reaction of Tetraethynylsilane. Chem. Eur. J. 2014, 20, 16448-16453.

112. Tang, W.; Becker, M.L. "Click" reactions: A versatile toolbox for the synthesis of peptide-conjugates. Chem. Soc. Rev. 2014, 43, 7013-7039.

113. Vieyres, A.; Lam, T.; Gillet, R.; Franc, G.; Castonguay, A.; Kakkar, A. Combined CuI-catalysed alkyne-azide cycloaddition and furan-maleimide Diels-Alder "click" chemistry approach to thermoresponsive dendrimers. Chem. Commun. 2010, 46, 1875-1877.

114. Polaske, N.W.; McGrath, D.V.; McElhanon, J.R. Thermally Reversible Dendronized Step-Polymers Based on Sequential Huisgen 1,3-Dipolar Cycloaddition and Diels-Alder "Click" Reactions. Macromolecules 2010, 43, 1270-1276.

115. Tonga, M.; Cengiz, N.; Kose, M.M.; Dede, T.; Sanyal, A. Dendronized polymers via Diels-Alder "click" reaction. J. Polym. Sci. Part. A: Polym. Chem. 2010, 48, 410-416.

116. Polaske, N.W.; McGrath, D.V.; McElhanon, J.R. Thermally reversible dendronized linear AB step-polymers via "Click" chemistry. Macromolecules 2011, 44, 3203-3210.

117. Tonga, M.; Tonga, G.Y.; Seber, G.; Gok, O.; Sanyal, A. Dendronized polystyrene via orthogonal double-click reactions. J. Polym. Sci. Part. A: Polym. Chem. 2013, 51, 5029-5037.

118. Gok, O.; Yigit, S.; Merve Kose, M.; Sanyal, R.; Sanyal, A. Dendron-polymer conjugates via the diels-alder "click" reaction of novel anthracene-based dendrons. J. Polym. Sci. Part. A: Polym. Chem. 2013, 51, 3191-3201.

119. Kempe, K.; Onbulak, S.; Schubert, U.S.; Sanyal, A.; Hoogenboom, R. pH degradable dendron-functionalized poly(2-ethyl-2-oxazoline) prepared by a cascade "double-click" reaction. Polym. Chem. 2013, 4, 3236-3244.

120. Adzima, B.J.; Kloxin, C.J.; DeForest, C.A.; Anseth, K.S.; Bowman, C.N. 3D Photofixation Lithography in Diels-Alder Networks. Macromol. Rapid Commun. 2012, 33, 2092-2096.

121. Chen, K.; Shu, Q.; Schmittel, M. Design strategies for lab-on-a-molecule probes and orthogonal sensing. Chem. Soc. Rev. 2015, 44, 136-160.

122. Majoral, J.-P.; Caminade, A.-M.; Maraval, V. The specific contribution of phosphorus in dendrimer chemistry. Chem. Commun. 2002, 2929-2942.

123. Gottis, S.; Rodriguez, L.-I.; Laurent, R.; Angurell, I.; Seco, M.; Rossell, O.; Majoral, J.-P.; Caminade, A.-M. Janus carbosilane/phosphorhydrazone dendrimers synthesized by the "click" Staudinger reaction. Tetrahedron Lett. 2013, 54, 6864-6867. 
124. Katir, N.; El Brahmi, N.; El Kadib, A.; Mignani, S.; Caminade, A.-M.; Bousmina, M.; Majoral, J.P. Synthesis of Onion-Peel Nanodendritic Structures with Sequential Functional Phosphorus Diversity. Chem. Eur. J. 2015, 21, 6400-6408.

125. Karver, M.R.; Weissleder, R.; Hilderbrand, S.A. Bioorthogonal Reaction Pairs Enable Simultaneous, Selective, Multi-Target Imaging. Angew. Chem. Int. Ed. 2012, 51, 920-922.

126. Dong, J.; Krasnova, L.; Finn, M.G.; Sharpless, K.B. Sulfur(VI) Fluoride Exchange (SuFEx): Another Good Reaction for Click Chemistry. Angew. Chem. Int. Ed. 2014, 53, 9430-9448.

127. Becer, C.R.; Hoogenboom, R.; Schubert, U.S. Click Chemistry beyond Metal-Catalyzed Cycloaddition. Angew. Chem. Int. Ed. 2009, 48, 4900-4908.

128. Nguyen, T.-T.-T.; Baumgarten, M.; Rouhanipour, A.; Räder, H.J.; Lieberwirth, I.; Müllen, K. Extending the Limits of Precision Polymer Synthesis: Giant Polyphenylene Dendrimers in the Megadalton Mass Range Approaching Structural Perfection. J. Am. Chem. Soc. 2013, 135, 4183-4186.

129. Räder, H.J.; Nguyen, T.-T.-T.; Müllen, K. MALDI-TOF Mass Spectrometry of Polyphenylene Dendrimers up to the Megadalton Range. Elucidating Structural Integrity of Macromolecules at Unrivaled High Molecular Weights. Macromolecules 2014, 47, 1240-1248.

130. Pu, Y.-J.; Yuan, H.; Yang, M.; He, B.; Gu, Z.-W. Synthesis of peptide dendrimers with polyhedral oligomeric silsesquioxane cores via click chemistry. Chin. Chem. Lett. 2013, 24, 917-920.

131. Tan, M.; Ye, Z.; Lindner, D.; Brady-Kalnay, S.M.; Lu, Z.-R. Synthesis and Evaluation of a Targeted Nanoglobular Dual-Modal Imaging Agent for MR Imaging and Image-Guided Surgery of Prostate Cancer. Pharm. Res. 2014, 31, 1469-1476.

132. Lamanna, G.; Smulski, C.R.; Chekkat, N.; Estieu-Gionnet, K.; Guichard, G.; Fournel, S.; Bianco, A. Multimerization of an Apoptogenic TRAIL-Mimicking Peptide by Using Adamantane-Based Dendrons. Chem. Eur. J. 2013, 19, 1762-1768.

133. Carberry, T.P.; Tarallo, R.; Falanga, A.; Finamore, E.; Galdiero, M.; Weck, M.; Galdiero, S. Dendrimer Functionalization with a Membrane-Interacting Domain of Herpes Simplex Virus Type 1: Towards Intracellular Delivery. Chem. Eur. J. 2012, 18, 13678-13685.

134. Tan, M.; Wu, X.; Jeong, E.-K.; Chen, Q.; Lu, Z.-R. Peptide-Targeted Nanoglobular Gd-DOTA Monoamide Conjugates for Magnetic Resonance Cancer Molecular Imaging. Biomacromolecules 2010, 11, 754-761.

135. Beckmann, H.S.G.; Wittmann, V. Azides in carbohydrate chemistry. In Organic Azides: Syntheses and Applications, 1st ed.; Brase, S. Banert, K. Eds.; John Wiley \& Sons: New York, NY, USA, 2010; pp. 469-490.

136. L'Haridon, L.; Mallet, J.-M. Carbohydrate-based dendrimers. Carbohydr. Chem. 2014, 40, 257-269.

137. Mellet, C.O.; Mendez-Ardoy, A.; Fernandez, J.M.G. Click Multivalent Glycomaterials: Glycoclusters, Glycodendrimers, Glycopolymers, Hybrid Glycomaterials, and Glycosurfaces. In Click Chemistry in Glycoscience: New Developments and Strategies; John Wiley \& Sons, Inc.: New York, NY, USA, 2013; pp. 143-182.

138. Kushwaha, D.; Dwivedi, P.; Kuanar, S.K.; Tiwari, V.K. Click reaction in carbohydrate chemistry: recent developments and future perspective. Curr. Org. Synth. 2013, 10, 90-135.

139. Smadhi, M.; de Bentzmann, S.; Imberty, A.; Gingras, M.; Abderrahim, R.; Goekjian, P.G. Expeditive synthesis of trithiotriazine-cored glycoclusters and inhibition of Pseudomonas aeruginosa biofilm formation. Beilstein J. Org. Chem. 2014, 10, 1981-1990. 
140. Ciobanu, M.; Huang, K.-T.; Daguer, J.-P.; Barluenga, S.; Chaloin, O.; Schaeffer, E.; Mueller, C.G.; Mitchell, D.A.; Winssinger, N. Selection of a synthetic glycan oligomer from a library of DNA-templated fragments against DC-SIGN and inhibition of HIV gp120 binding to dendritic cells. Chem. Commun. 2011, 47, 9321-9323.

141. Papp, I.; Dernedde, J.; Enders, S.; Riese, S.B.; Shiao, T.C.; Roy, R.; Haag, R. Multivalent Presentation of Mannose on Hyperbranched Polyglycerol and their Interaction with Concanavalin A Lectin. ChemBioChem 2011, 12, 1075-1083.

142. Weaver, L.G.; Singh, Y.; Vamvounis, G.; Wyatt, M.F.; Burn, P.L.; Blanchfield, J.T. Carbohydrate globules: molecular asterisk-cored dendrimers for carbohydrate presentation. Polym. Chem. 2014, 5, 1173-1179.

143. Dondoni, A.; Marra, A. Recent applications of thiol-ene coupling as a click process for glycoconjugation. Chem. Soc. Rev. 2012, 41, 573-586.

144. Ghirardello, M.; Öberg, K.; Staderini, S.; Renaudet, O.; Berthet, N.; Dumy, P.; Hed, Y.; Marra, A.; Malkoch, M.; Dondoni, A. Thiol-ene and thiol-yne-based synthesis of glycodendrimers as nanomolar inhibitors of wheat germ agglutinin. J. Polym. Sci. Part A: Polym. Chem. 2014, 52, 2422-2433.

145. Mei, H.; Ingale, S.A.; Seela, F. Pyrene and bis-pyrene DNA nucleobase conjugates: excimer and monomer fluorescence of linear and dendronized cytosine and 7-deazaguanine click adducts. Tetrahedron 2013, 69, 4731-4742.

146. Liu, H.; Torring, T.; Dong, M.; Rosen, C.B.; Besenbacher, F.; Gothelf, K.V. DNA-Templated Covalent Coupling of G4 PAMAM Dendrimers. J. Am. Chem. Soc. 2010, 132, 18054-18056.

147. Brunner, K.; Harder, J.; Halbach, T.; Willibald, J.; Spada, F.; Gnerlich, F.; Sparrer, K.; Beil, A.; Moeckl, L.; Braeuchle, C.; et al. Cell-Penetrating and Neurotargeting Dendritic siRNA Nanostructures. Angew. Chem. Int. Ed. 2015, 54, 1946-1949.

148. Schlick, K.H.; Morgan, J.R.; Weiel, J.J.; Kelsey, M.S.; Cloninger, M.J. Clusters of ligands on dendrimer surfaces. Bioorg. Med. Chem. Lett. 2011, 21, 5078-5083.

149. Yu, H.; Nie, Y.; Dohmen, C.; Li, Y.; Wagner, E. Epidermal Growth Factor-PEG Functionalized PAMAM-Pentaethylenehexamine Dendron for Targeted Gene Delivery Produced by Click Chemistry. Biomacromolecules 2011, 12, 2039-2047.

150. Arseneault, M.; Leung, N.L. C.; Fung, L.T.; Hu, R.; Morin, J.-F.; Tang, B.Z. Probing the dendritic architecture through AIE: challenges and successes. Polym. Chem. 2014, 5, 6087-6096.

151. Caminade, A.-M.; Turrin, C.-O.; Laurent, R.; Ouali, A.; Delavaux-Nicot, B. Dendrimers: Towards Catalytic, Material and Biomedical Uses; John Wiley \& Sons, Ltd: New York City, NY, USA, 2011; p. 566.

152. Svenson, S.; Tomalia, D.A. Dendrimers in biomedical applications-Reflections on the field. Adv. Drug. Deliv. Rev. 2005, 57, 2106-2129.

153. Mullen, D.G.; McNerny, D.Q.; Desai, A.; Cheng, X.-M.; DiMaggio, S.C.; Kotlyar, A.; Zhong, Y.; Qin, S.; Kelly, C.V.; Thomas, T.P.; et al. Design, synthesis, and biological functionality of a dendrimer-based modular drug delivery platform. Bioconjugate Chem. 2011, 22, 679-689.

154. Thomas, T.P.; Huang, B.; Choi, S.K.; Silpe, J.E.; Kotlyar, A.; Desai, A.M.; Zong, H.; Gam, J.; Joice, M.; Baker, J.R. Polyvalent Dendrimer-Methotrexate as a Folate Receptor-Targeted Cancer Therapeutic. Mol. Pharm. 2012, 9, 2669-2676. 
155. Caminade, A.-M.; Laurent, R.; Delavaux-Nicot, B.; Majoral, J.-P. “Janus” dendrimers: syntheses and properties. New J. Chem. 2012, 36, 217-226.

156. Acton, A.L.; Fante, C.; Flatley, B.; Burattini, S.; Hamley, I.W.; Wang, Z.; Greco, F.; Hayes, W. Janus PEG-Based Dendrimers for Use in Combination Therapy: Controlled Multi-Drug Loading and Sequential Release. Biomacromolecules 2013, 14, 564-574.

157. Lee, J.W.; Han, S.C.; Ji, W.H.; Jin, S.-H.; Kim, J.H. Synthesis of diblock codendrimer by double click chemistry. Bull. Korean Chem. Soc. 2012, 33, 4103-4108.

158. Choi, J.-W.; Cho, B.-K. Degree of chain branching-dependent assemblies and conducting behavior in ionic liquid crystalline Janus dendrimers. Soft Matter 2011, 7, 4045-4049.

159. Yeniad, B.; Naik, H.; Amir, R.J.; Koning, C.E.; Hawker, C.J.; Heise, A. Encoded dendrimers with defined chiral composition via "click" reaction of enantiopure building blocks. Chem. Commun. 2011, 47, 9870-9872.

160. Bao, G.-m.; Tanaka, K.; Ikenaka, K.; Fukase, K. Probe design and synthesis of $\operatorname{Gal} \beta(1 \rightarrow 3)[\mathrm{NeuAc} \alpha(2 \rightarrow 6)]$ GlcNAc$\beta(1 \rightarrow 2)$ Man motif of N-glycan. Bioorg. Med. Chem. 2010, $18,3760-3766$.

161. Sharma, A.; Neibert, K.; Sharma, R.; Maysinger, D.; Kakkar, A. Facile Construction of Multifunctional Nanocarriers Using Sequential Click Chemistry for Applications in Biology. Macromolecules 2011, 44, 521-529.

162. Ornelas, C.; Pennell, R.; Liebes, L.F.; Weck, M. Construction of a Well-Defined Multifunctional Dendrimer for Theranostics. Org. Lett. 2011, 13, 976-979.

163. Jee, J.-A.; Spagnuolo, L.A.; Rudick, J.G. Convergent Synthesis of Dendrimers via the Passerini Three-Component Reaction. Org. Lett. 2012, 14, 3292-3295.

164. Qin, T.; Wiedemair, W.; Nau, S.; Trattnig, R.; Sax, S.; Winkler, S.; Vollmer, A.; Koch, N.; Baumgarten, M.; List, E.J.W.; Müllen, K. Core, Shell, and Surface-Optimized Dendrimers for Blue Light-Emitting Diodes. J. Am. Chem. Soc. 2011, 133, 1301-1303.

165. Prachumrak, N.; Pojanasopa, S.; Tarsang, R.; Namuangruk, S.; Jungsuttiwong, S.; Keawin, T.; Sudyoadsuk, T.; Promarak, V. Synthesis and characterization of carbazole dendronized coumarin derivatives as solution-processed non-doped emitters and hole-transporters for electroluminescent devices. New J. Chem. 2014, 38, 3282-3294.

166. Mangione, M.I.; Spanevello, R.A.; Rumbero, A.; Heredia, D.; Marzari, G.; Fernandez, L.; Otero, L.; Fungo, F. Electrogenerated Conductive Polymers from Triphenylamine End-Capped Dendrimers. Macromolecules 2013, 46, 4754-4763.

167. Schlüter, A.D.; Rabe, J.P. Dendronized Polymers: Synthesis, Characterization, Assembly at Interfaces, and Manipulation. Angew. Chem. Int. Ed. 2000, 39, 864-883.

168. Frauenrath, H. Dendronized polymers-building a new bridge from molecules to nanoscopic objects. Prog. Polym. Sci. 2005, 30, 325-384.

169. Jung, H.; Carberry, T.P.; Weck, M. Synthesis of first- and second-generation poly(amide)-dendronized polymers via ring-opening metathesis polymerization. Macromolecules 2011, 44, 9075-9083.

170. Kumari, M.; Singh, A.K.; Kumar, S.; Achazi, K.; Gupta, S.; Haag, R.; Sharma, S.K. Synthesis of amphiphilic dendronized polymers to study their self-assembly and transport behavior. Polym. Adv. Technol. 2014, 25, 1208-1215. 
171. He, X.; Zhong, L.; Wu, X.; Cai, X.; Xie, M.; Lin, S.; Yan, D. Synthesis and self-assembly of amphiphilic brush-dendritic-linear poly[poly(ethylene glycol) methyl ether methacrylate]- $b$ polyamidoamine-b-poly(e-caprolactone) copolymers. J. Polym. Sci. Part. A: Polym. Chem. 2012, 50, 2841-2853.

172. Laurent, B.A.; Grayson, S.M. Synthesis of Cyclic Dendronized Polymers via Divergent "Graft-from" and Convergent Click "Graft-to" Routes: Preparation of Modular Toroidal Macromolecules. J. Am. Chem. Soc. 2011, 133, 13421-13429.

173. Zorn, A.-M.; Malkoch, M.; Carlmark, A.; Barner-Kowollik, C. High temperature synthesis of vinyl terminated polymers based on dendronized acrylates: a detailed product analysis study. Polym. Chem. 2011, 2, 1163-1173.

174. Del Barrio, J.; Oriol, L.; Alcala, R.; Sanchez, C. Photoresponsive poly(methyl methacrylate)- $b$ azodendron block copolymers prepared by ATRP and click chemistry. J. Polym. Sci. Part A: Polym. Chem. 2010, 48, 1538-1550.

175. Subramani, C.; Yesilbag, G.; Jordan, B.J.; Li, X.; Khorasani, A.; Cooke, G.; Sanyal, A.; Rotello, V.M. Recognition mediated encapsulation and isolation of flavin-polymer conjugates using dendritic guest moieties. Chem. Commun. 2010, 46, 2067-2069.

176. Walter, M.V.; Lundberg, P.; Hult, A.; Malkoch, M. Novel macrothiols for the synthesis of a structurally comprehensive dendritic library using thiol-ene click chemistry. J. Polym. Sci. Part A: Polym. Chem. 2011, 49, 2990-2995.

177. Percec, V.; Wilson, D.A.; Leowanawat, P.; Wilson, C.J.; Hughes, A.D.; Kaucher, M.S.; Hammer, D.A.; Levine, D.H.; Kim, A.J.; Bates, F.S.; et al. Self-Assembly of Janus Dendrimers into Uniform Dendrimersomes and Other Complex Architectures. Science 2010, 328, 1009-1014.

178. Zhang, S.; Sun, H.-J.; Hughes, A.D.; Draghici, B.; Lejnieks, J.; Leowanawat, P.; Bertin, A.; de Leon, L.O.; Kulikov, O.V.; Chen, Y.; et al. "Single-Single" Amphiphilic Janus Dendrimers Self-Assemble into Uniform Dendrimersomes with Predictable Size. ACS Nano 2014, 8, 1554-1565.

179. Percec, V.; Leowanawat, P.; Sun, H.-J.; Kulikov, O.; Nusbaum, C.D.; Tran, T.M.; Bertin, A.; Wilson, D.A.; Peterca, M.; Zhang, S.; et al. Modular Synthesis of Amphiphilic Janus Glycodendrimers and Their Self-Assembly into Glycodendrimersomes and Other Complex Architectures with Bioactivity to Biomedically Relevant Lectins. J. Am. Chem. Soc. 2013, 135, 9055-9077.

180. Raghupathi, K.R.; Azagarsamy, M.A.; Thayumanavan, S. Guest-Release Control in Enzyme-Sensitive, Amphiphilic-Dendrimer-Based Nanoparticles through Photochemical Crosslinking. Chem. Eur. J. 2011, 17, 11752-11760.

181. Gingras, M.; Raimundo, J.-M.; Chabre, Y.M. Cleavable Dendrimers. Angew. Chem. Int. Ed. 2007, $46,1010-1017$.

182. Gingras M. Degradable dendrimers. In Designing Dendrimers; John Wiley \& Sons: New York, NY, USA, 2011; pp. 403-462

183. Kohman, R.E.; Zimmerman, S.C. Degradable dendrimers divergently synthesized via click chemistry. Chem. Commun. 2009, 794-796.

184. Yu, Z.-Q.; Xu, X.-M.; Hong, C.-Y.; Wu, D.-C.; You, Y.-Z. A Responsive Hyperbranched Polymer Not Only Can Self-Immolate but Also Can Self-Cross-Link. Macromolecules 2014, 47, 4136-4143. 
185. Zhou, L.; Geng, J.; Wang, G.; Liu, J.; Liu, B. Facile synthesis of stable and water-dispersible multihydroxy conjugated polymer nanoparticles with tunable size by dendritic cross-linking. ACS Macro Lett. 2012, 1, 927-932.

186. Oberg, K.; Hed, Y.; Joelsson Rahmn, I.; Kelly, J.; Lowenhielm, P.; Malkoch, M. Dual-purpose PEG scaffolds for the preparation of soft and biofunctional hydrogels: the convergence between CuAAC and thiol-ene reactions. Chem. Commun. 2013, 49, 6938-6940.

187. Wu, X.; He, X.; Zhong, L.; Lin, S.; Wang, D.; Zhu, X.; Yan, D. Water-soluble dendritic-linear triblock copolymer-modified magnetic nanoparticles: preparation, characterization and drug release properties. J. Mater. Chem. 2011, 21, 13611-13620.

188. Mongkhontreerat, S.; Walter, M.V.; Cai, Y.; Brismar, H.; Hult, A.; Malkoch, M. Functional porous membranes from amorphous linear dendritic polyester hybrids. Polym. Chem. 2015, 6, 2390-2395.

189. Xiao, S.; Fu, N.; Peckham, K.; Smith, B.D. Efficient Synthesis of Fluorescent Squaraine Rotaxane Dendrimers. Org. Lett. 2010, 12, 140-143.

190. Antoni, P.; Robb, M.J.; Campos, L.; Montanez, M.; Hult, A.; Malmstrom, E.; Malkoch, M.; Hawker, C.J. Pushing the Limits for Thiol-Ene and CuAAC Reactions: Synthesis of a 6th Generation Dendrimer in a Single Day. Macromolecules 2010, 43, 6625-6631.

191. Walter, M.V.; Malkoch, M. Simplifying the synthesis of dendrimers: accelerated approaches. Chem. Soc. Rev. 2012, 41, 4593-4609.

192. Han, W.; Lin, B.; Yang, H.; Zhang, X. Synthesis of UV-curable hyperbranched polyurethane (meth)acrylate oligomers via thiol-ene "click" chemistry. J. Appl. Polym. Sci. 2013, 128, 4261-4270.

193. Conte, M.L.; Robb, M.J.; Hed, Y.; Marra, A.; Malkoch, M.; Hawker, C.J.; Dondoni, A. Exhaustive glycosylation, pegylation, and glutathionylation of a [G4]-ene48 dendrimer via photoinduced thiol-ene coupling. J. Polym. Sci. Part A: Polym. Chem. 2011, 49, 4468-4475.

194. Kang, T.; Khan, A.; Ohshimizu, K.; Hunt, J.N.; Sivanandan, K.; Amir, R.J.; Ueda, M.; Hawker, C.J. Facile access to internally functionalized denderimers by using efficient and orthogonal click reactions. Polym. Prepr. 2010, 51, 533-534.

195. Ma, X.; Zhou, Z.; Jin, E.; Sun, Q.; Zhang, B.; Tang, J.; Shen, Y. Facile Synthesis of Polyester Dendrimers as Drug Delivery Carriers. Macromolecules 2013, 46, 37-42.

196. García-Gallego, S.; Hult, D.; Olsson, J.V.; Malkoch, M. Fluoride-Promoted Esterification with Imidazolide-Activated Compounds: A Modular and Sustainable Approach to Dendrimers. Angew. Chem. Int. Ed. 2015, 54, 2416-2419.

197. Fuentes-Paniagua, E.; Hernandez-Ros, J.M.; Sanchez-Milla, M.; Camero, M.A.; Maly, M.; Perez-Serrano, J.; Copa-Patino, J.L.; Sanchez-Nieves, J.; Soliveri, J.; Gomez, R.; et al. Carbosilane cationic dendrimers synthesized by thiol-ene click chemistry and their use as antibacterial agents. RSC Adv. 2014, 4, 1256-1265.

198. Galan, M.; Fuentes-Paniagua, E.; de la Mata, F.J.; Gomez, R. Heterofunctionalized carbosilane dendritic systems: Bifunctionalized dendrons as building blocks versus statistically decorated dendrimers. Organometallics 2014, 33, 3977-3989.

199. Rissing, C.; Son, D.Y. Application of thiol-ene chemistry to the preparation of carbosilane-thioether dendrimers. Organometallics 2009, 28, 3167-3172.

200. Son, D.Y.; Rissing, C.; Chen, L.; Andersson, T.E. Thiol-ene chemistry for the synthesis and modification of branched organosilicon polymers. Polym. Prepr. 2010, 51, 730-731. 
201. Wong, E.H. H.; Altintas, O.; Stenzel, M.H.; Barner-Kowollik, C.; Junkers, T. Nitrone-mediated radical coupling reactions: A new synthetic tool exemplified on dendrimer synthesis. Chem. Commun. 2011, 47, 5491-5493.

202. Lewis, D.G.; Krasnova, L.B.; Skinner, P.J.; Fokin, V.V. Conductive dendrimers obtained by click chemistry. Proc. SPIE 2010, 7755, doi:10.1117/12.860879.

203. Hourani, R.; Sharma, A.; Kakkar, A. Designing dendritic frameworks using versatile building blocks suitable for CuI-catalyzed alkyne azide "click" chemistry. Tetrahedron Lett. 2010, 51, 3792-3795.

204. Wu, W.; Xu, G.; Li, C.; Yu, G.; Liu, Y.; Ye, C.; Qin, J.; Li, Z. From Nitro- to Sulfonyl-Based Chromophores: Improvement of the Comprehensive Performance of Nonlinear Optical Dendrimers. Chem. Eur. J. 2013, 19, 6874-6888.

205. Wu, W.; Ye, C.; Qin, J.; Li, Z. Dendrimers with Large Nonlinear Optical Performance by Introducing Isolation Chromophore, Utilizing the Ar/ArF Self-Assembly Effect, And Modifying the Topological Structure. ACS Appl. Mater. Interfaces 2013, 5, 7033-7041.

206. Wu, W.; Huang, Q.; Xu, G.; Wang, C.; Ye, C.; Qin, J.; Li, Z. Using an isolation chromophore to further improve the comprehensive performance of nonlinear optical (NLO) dendrimers. J. Mater. Chem. C 2013, 1, 3226-3234.

207. Rajakumar, P.; Anandhan, R.; Malathi, S.; Balasubramanian, S. Triazole-based ferrocenyl dendrimers as a medium for encapsulated palladium nanoparticles. Synlett 2013, 24, 575-580.

208. Rajakumar, P.; Kannan, A.; Anandhan, R. Synthesis, photophysical and electrochemical properties of 1,2,3-triazolyl bridged ferrocenyl dendrimers through click chemistry. New J. Chem. 2014, 38, 1594-1600.

209. Kato, S.-I.; Diederich, F. Non-planar push-pull chromophores. Chem. Commun. 2010, 46, 1994-2006.

210. Ganesh, V.; Sudhir, V.S.; Kundu, T.; Chandrasekaran, S. 10 Years of Click Chemistry: Synthesis and Applications of Ferrocene-Derived Triazoles. Chem. Asian J. 2011, 6, 2670-2694.

211. Djeda, R.; Rapakousiou, A.; Liang, L.; Guidolin, N.; Ruiz, J.; Astruc, D. Click Syntheses of 1,2,3-Triazolylbiferrocenyl Dendrimers and the Selective Roles of the Inner and Outer Ferrocenyl Groups in the Redox Recognition of $\mathrm{ATP}^{2-}$ and $\mathrm{Pd}^{2+}$. Angew. Chem. Int. Ed. 2010, 49, 8152-8156.

212. Liang, L.; Ruiz, J.; Astruc, D. "Click" Synthesis of a Heterobifunctional Ferrocenyl Dendrimer with Molecular Recognition Properties and Influence of the Ferrocenyl Redox Potential on the Formation of Gold Nanoparticles. J. Inorg. Organomet. Polym. Mater. 2010, 20, 503-510.

213. Astruc, D.; Ornelas, C.; Ruiz, J. "Click" synthesis of organo-silicon dendrimers. Main Group Chem. 2010, 9, 87-100.

214. Astruc, D.; Ornelas, C.; Rapakousiou, A.; Liang, L.; Djeda, R.; Ruiz, J. Redox recognition using click chemistry. Inorg. Chim. Acta 2011, 374, 51-58.

215. Rajakumar, P.; Anandhan, R.; Kannan, A. 1,2,3-Triazole Ferrocenyldendrimers Through Click Chemistry Approach and their Optical and Electrochemical Properties. Aust. J. Chem. 2012, 65, 1457-1462.

216. Astruc, D.; Liang, L.; Rapakousiou, A.; Ruiz, J. Click Dendrimers and Triazole-Related Aspects: Catalysts, Mechanism, Synthesis, and Functions. A Bridge between Dendritic Architectures and Nanomaterials. Acc. Chem. Res. 2012, 45, 630-640. 
217. Rapakousiou, A.; Wang, Y.; Belin, C.; Pinaud, N.; Ruiz, J.; Astruc, D. "Click” Synthesis and Redox Properties of Triazolyl Cobalticinium Dendrimers. Inorg. Chem. 2013, 52, 6685-6693.

218. Boisselier, E.; Diallo, A.K.; Salmon, L.; Ornelas, C.; Ruiz, J.; Astruc, D. Encapsulation and Stabilization of Gold Nanoparticles with "Click” Polyethyleneglycol Dendrimers. J. Am. Chem. Soc. 2010, 132, 2729-2742.

219. Nivoix, Y.; Ubeaud-Sequier, G.; Engel, P.; Levêque, D.; Herbrecht, R. Drug-drug interactions of triazole antifungal agents in multimorbid patients and implications for patient care. Curr. Drug. Metab. 2009, 10, 395-409.

220. Lass-Floerl, C. Triazole antifungal agents in invasive fungal infections: A comparative review. Drugs 2011, 71, 2405-2419.

(C) 2015 by the authors; licensee MDPI, Basel, Switzerland. This article is an open access article distributed under the terms and conditions of the Creative Commons Attribution license (http://creativecommons.org/licenses/by/4.0/). 